\title{
Article
}

\section{Free Convection Heat Transfer from Horizontal Cylinders}

\author{
Janusz T. Cieśliński ${ }^{1, *}$,, Slawomir Smolen ${ }^{2}$ and Dorota Sawicka ${ }^{2}$ \\ 1 Faculty of Mechanical and Ocean Engineering, Gdańsk University of Technology, Narutowicza 11/12, \\ 80233 Gdansk, Poland \\ 2 Faculty of Nature and Engineering, City University of Applied Sciences Bremen, Neustadtswall 30, \\ 28199 Bremen, Germany; Slawomir.Smolen@hs-bremen.de (S.S.); dorota.czerwonka@gmail.com (D.S.) \\ * Correspondence: jcieslin@pg.edu.pl
}

check for

updates

Citation: Cieśliński, J.T.; Smolen, S.; Sawicka, D. Free Convection Heat Transfer from Horizontal Cylinders. Energies 2021, 14, 559. https:// doi.org/10.3390/en14030559

Received: 6 December 2020

Accepted: 19 January 2021

Published: 22 January 2021

Publisher's Note: MDPI stays neutral with regard to jurisdictional claims in published maps and institutional affiliations.

\begin{abstract}
The results of experimental investigation of free convection heat transfer in a rectangular container are presented. The ability of the commonly accepted correlation equations to reproduce present experimental data was tested as well. It was assumed that the examined geometry fulfils the requirement of no-interaction between heated cylinder and bounded surfaces. In order to check this assumption recently published correlation equations that jointly describe the dependence of the average Nusselt number on Rayleigh number and confinement ratios were examined. As a heat source served electrically heated horizontal tube immersed in an ambient fluid. Experiments were performed with pure ethylene glycol (EG), distilled water (W), and a mixture of EG and water at $50 \% / 50 \%$ by volume. A set of empirical correlation equations for the prediction of $\mathrm{Nu}$ numbers for Rayleigh number range $3.6 \times 10^{4}<\mathrm{Ra}<9.2 \times 10^{5}$ or $3.6 \times 10^{5}<\mathrm{Ra}_{\mathrm{q}}<14.8 \times 10^{6}$ and Pr number range $4.5 \leq \operatorname{Pr} \leq 160$ has been developed. The proposed correlation equations are based on two characteristic lengths, i.e., cylinder diameter and boundary layer length.
\end{abstract}

Keywords: free convection; horizontal cylinder; experiment; correlation equations

\section{Introduction}

Free convection heat transfer from heated horizontal cylinders immersed in an extensive (infinite, unbounded), quiescent fluid has been intensively studied for decades [1]. However, in industry as well as in laboratory practice, the condition of no-interaction between the heated cylinder and bounded surfaces is often not fulfilled. Free convection flows generated by a heated body immersed in a bulk of fluid are bounded by the side (horizontal) walls, ceiling (vertical confinement) or free surface of the liquid, and bottom wall. Morgan [2] suggests that discrepancy between experimental data presented in literature may be attributed to "an undersized containment volume". Many analytical, numerical and experimental studies have been conducted in order to clarify the impact of confinement on free convection heat transfer performance from horizontal, heated cylinders immersed in a fluid. Following the model proposed by Churchill and Usagi [3], Churchill and Chu [4] developed one of the most famous correlation equation for the mean value of $\mathrm{Nu}$ over the cylinder for all Ra numbers and all Pr numbers, which is applicable for uniform heating as well as for uniform wall temperature-Equation $(1 \mathrm{a}, \mathrm{b})$ in Table 1 . However, as it was pointed out by Morgan [5], the correlation of Churchill and Chu gives lower values of $\mathrm{Nu}$ than other correlations for a fixed value of Ra. Moreover, Nu numbers do not approach zero as Ra approaches zero. Morgan [2] proposed an empirical correlation over the whole range of Rayleigh numbers, except possibly in the transition regions at Ra values of $10^{-2}$, $10^{2}, 10^{4}$, and $10^{7}$-Equation (2) in Table 1 . Kuehn and Goldstein [6] proposed analytically based correlation for free convection heat transfer from a horizontal cylinder which is valid at any Rayleigh and Prandtl number-Equation (3) in Table 1. Fand et al. [7] proposed an experimentally based correlation for free convection heat transfer from horizontal cylinders immersed in an infinite fluid where the confinement ratios of the tested geometry 
were: $\mathrm{H}_{\mathrm{T}} / \mathrm{D}=78.8, \mathrm{H}_{\mathrm{B}} / \mathrm{D}=30.8, \mathrm{~S}_{\mathrm{W}} / \mathrm{D}=8.4$ and $\mathrm{L} / \mathrm{D}=7.6$-Equation $(4 \mathrm{a}-\mathrm{c})$ in Table 1 . Kuehn and Goldstein [8] stated that the position of the outer boundary has an effect on the calculated values of heat transfer coefficient if it is not set far enough from the surface of the cylinder. The distance depends on the Ra and Pr numbers and should be between $\mathrm{D}<\mathrm{R}_{\infty}<20 \mathrm{D}$. Farouk and Güçeri [9] established numerically that the outer boundary depends on the Ra number. For $\mathrm{Ra} \leq 10^{4}, \mathrm{R}_{\infty}=16 \mathrm{D}$ was used, but for $\mathrm{Ra}=10^{7}$ the radius of the pseudo boundary decreased to $R_{\infty}=8 \mathrm{D}$. Results obtained for $\operatorname{Pr}=0.721$ show good agreement with published experimental data. Fand and Brucker [10] proposed a correlation which represents the $\mathrm{Nu}$ number as a function of Ra and Pr numbers, and a parameter that accounts for viscous dissipation-Equation (5) in Table 1. Sparrow and Pfeil [11] observed heat transfer enhancement (up to $40 \%$ ) for a cylinder placed in a container compared with a cylinder placed in an infinite volume of air. The confinement ratios of the tested geometry were: $5<\mathrm{H} / \mathrm{D}<20,0.75<\mathrm{S}_{\mathrm{W}} / \mathrm{D}<5$ and $\mathrm{L} / \mathrm{D}=20$. Maximum enhancement was obtained for minimum $S_{W}$ and maximum $H$. No enhancement was observed for $\mathrm{S}_{\mathrm{W}} / \mathrm{D}>5$. Sparrow and Ansari [12] experimentally investigated impact of the vertical wall spacing $\left(4 / 3<S_{W} / D<1 / 12\right)$ and bottom wall spacing $\left(4 / 3<S_{W} / D<1 / 12\right)$ on heat transfer from horizontal cylinder. The smallest tested distance between the cylinder periphery and the vertical wall was the cylinder diameter. The confinement ratio was equal to $\mathrm{L} / \mathrm{D}=20$. It was established that the smaller was the spacing the higher was the heat transfer degradation. A side wall caused maximum reduction of about $20 \%$. The reductions in heat transfer for spacings greater than $\mathrm{D}$ were negligible. A bottom wall caused reductions of about $5 \%$ greater than those due to the side wall. The corner configurations generated reductions up to $40 \%$. Warrington and Powe [13] studied experimentally free convection heat transfer from short isothermal cylinders $(0.51<\mathrm{L} / \mathrm{D}<0.86)$ placed in a cubical enclosure $(\mathrm{H}=26.67 \mathrm{~cm})$. It was established that, contrary to the enclosure shape (cubical or spherical) and flow patterns, the enclosure dimensions have a meaningful impact on heat transfer performance. Warrington and Powe proposed an empirical correlation as a function of Ra and Pr numbers, and dimensionless geometric parameters-Equation (6a) in Table 1. Karim et al. [14] conducted an experimental study on free convection heat transfer from horizontal cylinders $(\mathrm{D}=3.81 \mathrm{~cm}$ and $\mathrm{D}=2.54 \mathrm{~cm})$ to air were the confinement ratios of the tested geometry were: $\mathrm{H}_{\mathrm{T}} / \mathrm{D}=32$ or $48, \mathrm{H}_{\mathrm{B}} / \mathrm{D}=24$ or $42,0.75<\mathrm{S}_{\mathrm{W}} / \mathrm{D}=6$ and $\mathrm{L} / \mathrm{D}=$ 17.1 or 26 . It was found that the presence of the vertical adiabatic walls improves the heat transfer from the cylinder up to $45 \%$ for the smallest $\mathrm{Ra}$ and $\mathrm{S}_{\mathrm{W}} / \mathrm{D}$ studied. An empirical correlation was proposed to describe the dependence of the average Nusselt number on $\mathrm{Ra}$ and $S_{W} / D$ jointly-Equation (7) in Table 1. Warrington et al. [15] proposed an equation that defines the gap width (confinement ratio) over which the equations for free convection heat transfer in an unbounded medium are advised. Ghaddar [16] carried out numerical study on free convection heat transfer from horizontal cylinder to air. The confinement ratios of the tested $2 \mathrm{D}$ geometry were: $\mathrm{H} / \mathrm{D}=40, \mathrm{H}_{\mathrm{B}} / \mathrm{D}=10, \mathrm{~S}_{\mathrm{W}} / \mathrm{D}=7.5$. It was established that equation based on the hypothetical gap width-Equation (8a) in Table 1 , correlates the results much better than equation based on the boundary layer length. Saitoh et al. [17] presented numerical calculations for free convection heat transfer from a cylinder with uniform surface temperature and $10^{3}<\mathrm{Ra}<10^{5}$. They stressed that the radial distance between cylinder surface and outer boundary of the solution domain is a key factor in determination of the heat transfer from the cylinder. It was established that the minimum distance over which there is no influence of the outer boundary on the heat transfer is equal to 700D. Moukalled and Acharya [18] conducted a numerical study for free convection heat transfer from a heated horizontal cylinder placed concentrically inside a square cavity of small confinement ratios $1.7<\mathrm{H} / \mathrm{D}<5$. It was established that at constant confinement ratio heat transfer enhancement was observed with Ra number increase. A correlation equation has been proposed to capture the dependence of the average Nusselt number on Ra and H/D jointly. Kitamura et al. [19] conducted experimental study of free convection from large diameter cylinders $6 \mathrm{~cm} \leq \mathrm{D} \leq 80 \mathrm{~cm}$ in water. The confinement ratios of the tested geometry were: $0.19<\mathrm{H}_{\mathrm{T}} / \mathrm{D}<14.8,1.6<\mathrm{S}_{\mathrm{W}} / \mathrm{D}<21$ and 
$0.63 \leq \mathrm{L} / \mathrm{D} \leq 8.3$. The bottom generatrix of the cylinder was located $\mathrm{H}_{\mathrm{B}}=300 \mathrm{~mm}$ above the horizontal base plate. The tested cylinders were heated with constant heat flux. The results show that, the maximum local heat transfer coefficient occurs in the transitional region. Two correlation equations were proposed with modified Rayleigh numbers based on heat flux-Equation (9) in Table 1. Cesini et al. [20] performed numerical and experimental analysis for free convection heat transfer from a horizontal cylinder located at the centre of the rectangular cavity. The confinement ratios of the tested geometry were: $\mathrm{H} / \mathrm{D}=4.1, \mathrm{H}_{\mathrm{T}} / \mathrm{D}=\mathrm{H}_{\mathrm{B}} / \mathrm{D}=21.5,8<\mathrm{S}_{\mathrm{W}} / \mathrm{D}<18$ and $\mathrm{L} / \mathrm{D}=30$. The experiments and numerical calculations were conducted with air and Rayleigh number range from $1.3 \times 10^{3}$ to $3.4 \times 10^{3}$, and $1.3 \times 10^{3}$ to $7.5 \times 10^{4}$, respectively. It was established that the Rayleigh number increase results in a mean heat transfer coefficient increase, whose maximum was found at decreasing $S_{W} / D$ values. Sadeghipour and Razi [21] studied analytically, numerically, and experimentally free convection heat transfer from an isothermal cylinder $(\mathrm{L} / \mathrm{D}=66.7)$ placed between vertical walls. The confinement ratio $\mathrm{H} / \mathrm{D}=7$ was constant, while the dimensionless distance between vertical walls ranged between $1.5<\mathrm{W} / \mathrm{D}<12$. An optimum wall spacing corresponding to the maximum rate of heat transfer was determined. The optimum value of $\mathrm{W} / \mathrm{D}$ ratio was obtained for lower Rayleigh numbers considered. An analytically developed correlation equation as a function of the Ra number and the W/D ratio has been proposed-Equation (10) in Table 1. Atmane et al. [22] experimentally investigated the effect of vertical confinement on free convection heat transfer around a horizontal heated cylinder. Of particular interest was the influence of the distance between the free water surface and the top of the cylinder on heat transfer from the cylinder. Three submersion depths $\mathrm{H}_{\mathrm{T}}$ were investigated: $\mathrm{H}_{\mathrm{T}} / \mathrm{D}=0.5, \mathrm{H}_{\mathrm{T}} / \mathrm{D}=1$ and $\mathrm{H}_{\mathrm{T}} / \mathrm{D}$ $=3$. The confinement ratios of the tested geometry were: $H / D=23.3, S_{W} / D=4.5$ and $\mathrm{L} / \mathrm{D}=9$. The experiments were conducted for Rayleigh numbers ranging from $3.1 \times 10^{6}$ to $4.1 \times 10^{6}$. It was established that for dimensionless submersion water depths above $\mathrm{H}_{\mathrm{T}} / \mathrm{D}=3$, heat transfer was not influenced by the water surface. On the other hand, for the smallest studied dimensionless submersion depth $\left(\mathrm{H}_{\mathrm{T}} / \mathrm{D}=1 / 5\right)$ considerable heat transfer degradation has been observed. Ashjaee et al. [23] experimentally studied the impact of an adiabatic ceiling on steady $2 \mathrm{D}$ free convection heat transfer from a horizontal, isothermal cylinder to air. Three cylinders of 10, 19.5 and $22 \mathrm{~mm}$ O.D. were used. In order to eliminate $3 \mathrm{D}$ effect, the length to diameter ratio of each cylinder was $\mathrm{L} / \mathrm{D}=16$. Experiments were performed for $0.1 \leq \mathrm{H}_{\mathrm{T}} / \mathrm{D} \leq 2.4$. In order to eliminate the impact of the side vertical wall on heat transfer from the cylinder the dimensionless distance was chosen to be $S_{W} / D=$ 9.5. It was shown that heat transfer performance depends on the dimensionless distance $\mathrm{H}_{\mathrm{T}} / \mathrm{D}$. For $\mathrm{H}_{\mathrm{T}} / \mathrm{D} \geq 1.5$ no influence of the adiabatic ceiling on free convection heat transfer from the cylinder was observed. For $0.5 \leq \mathrm{H}_{\mathrm{T}} / \mathrm{D} \leq 1.5$ heat transfer degradation was noticed. But for $\mathrm{H}_{\mathrm{T}} / \mathrm{D}<0.5$ heat transfer enhancement was observed. It was established that optimum spacing for which heat transfer rate from the cylinder reaches the minimum depends on the Rayleigh number. Moreover, at the optimum wall spacing the average Nusselt number is lower of about $19 \%$ in comparison to the unbounded medium case. A correlation equation which relates the Nusselt number against the Rayleigh number and $\left(\mathrm{H}_{\mathrm{T}} / \mathrm{D}\right)$ jointly has been proposed-Equation (11) in Table 1. Atayllmaz and Teke [24] conducted an experimental and numerical study on free convection heat transfer from two cylinders with L/D = 208.3 and 105.8. Experiments were conducted at constant heat flux in air. In order to eliminate impact of the container walls the confinements ratio were equal to $H / D=137.6$ or 270.8 and $W / D=166.7$ or 84.7 . An empirical correlation equation for the Nusselt number is proposed for very small Rayleigh numbers $74 \leq \mathrm{Ra} \leq 3400$. Angeli et al. [25] conducted 2D numerical, parametric study for free convection from a horizontal cylinder concentrically placed in a square cavity. The confinement ratios of the cavity were $\mathrm{H} / \mathrm{D}=5,2.5,1.67$, and 1.25 , so the corresponding dimensionless distances are: $\mathrm{H}_{\mathrm{T}} / \mathrm{D}=\mathrm{S}_{\mathrm{W}} / \mathrm{D}=2,0.75,0.333,0.125$. A correlation equation for the average Nusselt number as a function of both the Rayleigh number and the dimensionless distance $\mathrm{H}_{\mathrm{T}} / \mathrm{D}$ has been developed. As the characteristic length the gap width, i.e., the distance $\mathrm{H}_{\mathrm{T}}$ has 
been proposed. Kim et al. [26] investigated numerically the effect of the cylinder location on the heat transfer and air flow in a $2 \mathrm{D}$ square cavity with $\mathrm{H} / \mathrm{D}=2.5$. The dimensionless vertical position of the cylinder varied within the range $(-0.25 \leq \Delta \mathrm{H} / \mathrm{H} \leq+0.25)$. The range of the Rayleigh numbers was $\left(10^{3} \leq \mathrm{R} \leq 10^{6}\right)$. It was established that when $\mathrm{Ra}=$ $10^{5}$ and $10^{6}$ the effect of the cylinder position on heat transfer is negligible. Yoon et al. [27] carried out detailed numerical calculations for free convection heat transfer and the geometry described in [26], but for the Rayleigh number of $\mathrm{Ra}=10^{7}$. It was established that at $\mathrm{Ra}=10^{7}$ the flow patterns in the enclosure depend on the location of the cylinder. Free convection becomes unsteady or steady depending on the distance of the cylinder from the isothermal ceiling or isothermal bottom wall.

Angeli et al. [28] conducted numerical analysis of air free convection from a horizontal cylinder concentrically placed in a square cavity. The calculations were performed for three values of the aspect ratio $\mathrm{H}_{\mathrm{T}} / \mathrm{H}=0.4,03$ and 0.2 . A correlation equation for the average Nusselt number as a function of both the Rayleigh number and the aspect ratio, with the distance $\mathrm{H}_{\mathrm{T}}$ as the characteristic length, has been proposed. Ashjaee et al. [29] studied experimentally and numerically $2 \mathrm{D}$ free convection from horizontal heated cylinders placed above an adiabatic bottom. The experimental study was performed in air for the spacing 0 $\leq \mathrm{H}_{\mathrm{B}} / D \leq 0.9$. The numerical investigation was conducted for $0.1 \leq \mathrm{H}_{\mathrm{B}} / D \leq 1.7$. In order to minimize the influence of the vertical walls on heat transfer the dimensionless distance was chosen to be $S_{W} / D=9.5$. It was established that Nusselt number increases with Ra number increase and $\mathrm{H}_{\mathrm{B}} / \mathrm{D}$ increase, and limit for the Nusselt number is the value for the cylinder in unbounded air. Furthermore, for $\mathrm{H}_{\mathrm{B}} / \mathrm{D} \geq 1.1$ there is no influence of the adiabatic bottom on heat transfer performance. A correlation based on the numerical data for the average Nusselt number as a function of Rayleigh number and $H_{B} / D$ has been proposed-Equation (12) in Table 1.

Kang et al. [30] continued the numerical study of Yoon at al. [27] regarding the impact of the location of a cylinder on heat transfer in an enclosure with isothermal walls for a Rayleigh number $\mathrm{Ra}=10^{7}$. The position of the cylinder changed along a horizontal or diagonal line. The dimensionless horizontal position of the cylinder varied in the range $\left(-0.25 \leq \Delta \mathrm{S}_{\mathrm{W}} / \mathrm{W} \leq 0\right)$, and the dimensionless diagonal position of the cylinder varied from $-0.25 \sqrt{2} H$ to $+0.25 \sqrt{2} H$. Sebastian and Shine [31] numerically studied the influence of the adiabatic ceiling and isothermal bottom wall on free convection from a horizontal heated cylinder. The dimensionless confinement ratios tested were $0.05<$ $\mathrm{H}_{\mathrm{T}} / \mathrm{D}=\mathrm{H}_{\mathrm{B}} / \mathrm{D}<5$. In order to avoid impact of the outer boundary on the heat transfer for isolated cylinder the computational domain was assumed to be 40D. It was observed that the adiabatic ceiling causes a reduction in the Nu number for all Ra in comparison to an isolated cylinder. It was shown that influence of the confinement depends on $\mathrm{H} / \mathrm{D}$ ratio. For high Ra numbers and small H/D ratios confinement effect vanishes. A correlation equation for local Nusselt number $\mathrm{Nu}_{\theta}$ around the isolated cylinder has been proposed. Abou-Ziyan et al. [32] conducted an experimental study of free convection from horizontal cylinder of small aspect ratio L/D $=8$ on three Newtonian and two non-Newtonian liquids. Electrically heated tube fulfils the condition of constant heat flux. Because of the confinement ratios applied: $\mathrm{H} / \mathrm{D}=112, \mathrm{H}_{\mathrm{T}} / \mathrm{D}=8$ and tank depth (l) to cylinder diameter (D) $1 / \mathrm{D}=32$, it was assumed that the effect of horizontal (1/D) and vertical confinements $\left(\mathrm{H}_{\mathrm{T}} / \mathrm{D}\right)$ on free convective heat transfer can be neglected. It was established that the heat transfer performance depends on the thermophysical properties of the bulk liquid and of the liquid layer in the vicinity of the cylinder. The developed correlation for the Nusselt number $\mathrm{Nu}$ is dependent on a number of interrelated variables such as Grashof number based on heat flux, $\mathrm{Pr}, \mathrm{Pr}_{\mathrm{f}} / \mathrm{Pr}_{\mathrm{w}}$ and heat generation parameter-Equation (13) in Table 1. Rath et al. [33] performed a 2D numerical study on free convection from horizontal cylinders of different shapes in a rectangular cavity $(57 \times 30 \mathrm{~mm})$ in laminar regime for a Rayleigh number in the range of $\left(10^{3} \leq R a \leq 10^{6}\right)$. The confinement ratio was W/D $=2.1$. It was established that the Nusselt numbers strongly depend on the shape of the cylinder. For cylinders of the same surface area the $\mathrm{Nu}$ numbers for a circular cylinder were 
distinctly higher than for a triangular cylinder or a square cylinder. Correlations based on numerical calculations for the average Nusselt numbers for three shapes of cylinders have been proposed. Lin et al. [34] proposed for the first time a 3D model to predict the $\mathrm{Nu}$ numbers for a horizontal isothermal cylinder of $\mathrm{L} / \mathrm{D}=23.6$. The calculations were conducted for water assuming constant Prandtl number of 5.98. The confinement walls were isothermal with the top water surface open to air. The Rayleigh numbers varied from $10^{5}$ to $5 \times 10^{6}$. The dimensionless submersion depth was $\mathrm{H}_{\mathrm{T}} / \mathrm{D}=6$. Excellent agreement between published data and calculated results regarding flow patterns and heat transfer characteristics have been observed. Ma et al. [35] studied numerically thermal plumes generated by a single heated cylinder during free convection. Laminar as well as turbulent flows were investigated by applying different turbulent models. The results were compared to the literature data. Finally, influence of the horizontal pitch on free convection from single row of the heated cylinders were studied.

Table 1. Literature correlation equations.

\begin{tabular}{|c|c|c|c|c|}
\hline $\begin{array}{c}\text { Authors } \\
\text { [Reference] }\end{array}$ & Equation & Nu-Ra Relationship & $\begin{array}{c}\text { Ra and Pr Range; } \\
t_{c h} \text { and } L_{c h}\end{array}$ & $\begin{array}{c}\text { Surface } \\
\text { Condition }\end{array}$ \\
\hline \multirow[t]{3}{*}{$\begin{array}{l}\text { Churchill and Chu } \\
{[4]}\end{array}$} & \multirow[t]{3}{*}{$\begin{array}{l}\text { Equation (1a) } \\
\text { Equation (1b) }\end{array}$} & $N u=\left(0.6+\frac{0.387 \times R a^{\frac{1}{6}}}{\left[1+\left(\frac{0.559}{P r}\right)^{\frac{9}{16}}\right]^{\frac{8}{27}}}\right)^{2}$ & $10^{-7}<R a<10^{13}$ & \multirow[t]{3}{*}{$\begin{array}{l}t_{\text {uni }} \\
\text { and } \\
\text { quni }\end{array}$} \\
\hline & & $N u=0.6+\frac{0.387 \times\left(R a_{q} / N u\right)^{1 / 6}}{97^{\frac{8}{27}}}$ & $t_{c h}=t_{f m}$ & \\
\hline & & & $\mathrm{L}_{\mathrm{ch}}=\mathrm{D}$ & \\
\hline \multirow{4}{*}{ Morgan [2] } & \multirow{4}{*}{ Equation (2) } & \multirow{4}{*}{$\begin{array}{c}\mathrm{Nu}=B R a^{m} \\
\mathrm{~B}=1.02 \text { and } \mathrm{m}=0.148,10^{-2}<R a \leq 10^{2} \\
\mathrm{~B}=0.85 \text { and } \mathrm{m}=0.188,10^{2}<R a \leq 10^{4} \\
\mathrm{~B}=0.48 \text { and } \mathrm{m}=0.25,10^{4}<R a \leq 10^{7} \\
\mathrm{~B}=0.125 \text { and } \mathrm{m}=0.333,10^{7}<R a \leq 10^{12}\end{array}$} & $10^{-2} \leq R a \leq 10^{12}$ & \multirow{4}{*}{$t_{\text {uni }}$} \\
\hline & & & $\mathrm{Pr}$-not stated & \\
\hline & & & $\mathrm{t}_{\mathrm{ch}}=\mathrm{t}_{\mathrm{fm}}$ & \\
\hline & & & $\mathrm{L}_{\text {char }}=\mathrm{D}$ & \\
\hline \multirow{8}{*}{$\begin{array}{l}\text { Kuehn and } \\
\text { Goldstein [6] }\end{array}$} & \multirow{4}{*}{ Equation (3) } & \multirow{4}{*}{\begin{tabular}{l|l|l}
$0.518 R a^{\frac{1}{4}}$ & $1+\left(\frac{0.559}{P r}\right)^{\frac{5}{2}}$ \\
& $\left.+0.1 R a^{\frac{1}{3}}\right)$ \\
\end{tabular}} & any $R a$ & \multirow{4}{*}{$t_{\text {uni }}$} \\
\hline & & & any $\operatorname{Pr}$ & \\
\hline & & & $\mathrm{t}_{\mathrm{ch}}-$ not stated & \\
\hline & & & $\mathrm{L}_{\mathrm{ch}}=\mathrm{D}$ & \\
\hline & \multirow{4}{*}{ Equation (4a) } & \multirow{4}{*}{$\begin{array}{c}N u_{n}=0.456 R a_{y}^{0.25} \operatorname{Pr}_{p}^{0.057} \\
N u_{n}=N u_{w}\left(\frac{N u_{\infty}}{N u_{w}}\right)^{0.20} R a_{y}=R a_{w}\left(\frac{R a_{\infty}}{R a_{w}}\right)^{0.50} \operatorname{Pr}_{p}=\operatorname{Pr}_{w}\left(\frac{P r_{\infty}}{P r_{w}}\right)^{0.50}\end{array}$} & $\begin{array}{c}2.5 \times 10^{2} \leq R a< \\
2 \times 10^{7}\end{array}$ & \multirow{4}{*}{$t_{\text {uni }}$} \\
\hline & & & $0.7<\operatorname{Pr}<3090$ & \\
\hline & & & $\mathrm{t}_{\mathrm{ch}}=\mathrm{t}_{\infty}$ and $\mathrm{t}_{\mathrm{ch}}=\mathrm{t}_{\mathrm{w}}$ & \\
\hline & & & $\mathrm{L}_{\mathrm{ch}}=\mathrm{D}$ & \\
\hline \multirow[t]{2}{*}{$\begin{array}{c}\text { Fand, Morris, Lum } \\
{[7]}\end{array}$} & Equation (4b) & $N u=0.478 R a^{0.25} \mathrm{Pr}^{0.05}$ & $\begin{array}{c}\mathrm{t}_{\text {char }}=\mathrm{t}_{\infty}+0.32\left(\mathrm{t}_{\mathrm{w}}-\right. \\
\left.\mathrm{t}_{\infty}\right)\end{array}$ & \\
\hline & Equation (4c) & $N u=0.474 R a^{0.25} \mathrm{Pr}^{0.047}$ & $t_{c h}=t_{f m}$ & $t_{\text {uni }}$ \\
\hline \multirow{4}{*}{$\begin{array}{c}\text { Fand and Brucker } \\
{[10]}\end{array}$} & \multirow{4}{*}{ Equation (5) } & \multirow{4}{*}{ 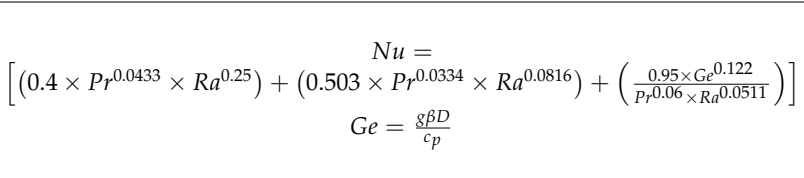 } & $10^{-8} \leq R a \leq 10^{8}$ & \\
\hline & & & $0.7<\operatorname{Pr}<4 \times 10^{4}$ & \\
\hline & & & $t_{c h}=t_{f m}$ & \\
\hline & & & $\mathrm{L}_{\mathrm{ch}}=\mathrm{D}$ & \\
\hline
\end{tabular}


Table 1. Cont.

\begin{tabular}{|c|c|c|c|c|}
\hline $\begin{array}{c}\text { Authors } \\
\text { [Reference] }\end{array}$ & Equation & Nu-Ra Relationship & $\begin{array}{l}\text { Ra and } \operatorname{Pr} \text { Range; } \\
t_{c h} \text { and } L_{c h}\end{array}$ & $\begin{array}{c}\text { Surface } \\
\text { Condition }\end{array}$ \\
\hline \multirow[t]{3}{*}{$\begin{array}{l}\text { Warrington and } \\
\text { Powe [13] }\end{array}$} & Equation (6a) & $\begin{array}{c}\quad N u_{G}=1.45 R a_{G}^{* 0.284} \\
\qquad a_{G}^{*}=R a_{G}\left(G / R_{i}\right), G=R_{o}-R_{i} \\
R_{i} \text {-hypothetical radius of an inner sphere of a volume equal to the } \\
\text { cylindrical body } \\
R_{0} \text { - outer body hypothetical radius equal to the radius of a sphere having } \\
\text { a volume equal to the volume of the outer body }\end{array}$ & 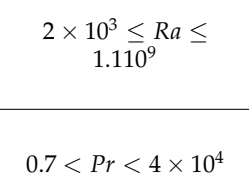 & \multirow[t]{3}{*}{$t_{\text {uni }}$} \\
\hline & \multirow{2}{*}{ Equation (6b) } & \multirow{2}{*}{$N u_{b}=0.954 R a_{b}^{0.208}$} & $t_{c h}=t_{f m}$ & \\
\hline & & & $\mathrm{L}_{\mathrm{ch}}=\mathrm{G}$ & \\
\hline \multirow{4}{*}{ Karim et al. [14] } & \multirow{4}{*}{ Equation (7) } & \multirow{4}{*}{$N u=\left[0.481+0.172 \times \exp \left(-0.258 \times\left(\frac{W}{D}\right)\right)\right] \times R a^{0.25}$} & $\begin{array}{c}2 \times 10^{3} \leq R a \leq \\
3 \times 10^{5.5}\end{array}$ & \multirow{4}{*}{$t_{\text {uni }}$} \\
\hline & & & $\operatorname{Pr}=0.7$ & \\
\hline & & & $t_{c h}=t_{f m}$ & \\
\hline & & & $\mathrm{L}_{\mathrm{ch}}=\mathrm{D}$ & \\
\hline \multirow{8}{*}{ Ghaddar [16] } & \multirow{4}{*}{ Equation (8a) } & \multirow{4}{*}{$\begin{array}{c}N u_{G}=1.81 R a_{G}^{* 0.207} \\
R a_{G}^{*} \text {-see Equation (6a) }\end{array}$} & $10^{7}<R a_{G}^{*} \leq 10^{10}$ & \multirow{8}{*}{ quni } \\
\hline & & & $\operatorname{Pr}=0.7$ & \\
\hline & & & $t_{c h}=t_{f m}$ & \\
\hline & & & $\mathrm{L}_{\mathrm{ch}}=\mathrm{G}$ & \\
\hline & \multirow{4}{*}{ Equation (8b) } & \multirow{4}{*}{$N u_{b}=0.604 R a_{b}^{0.2083}$} & $10<R a_{b} \leq 10^{3}$ & \\
\hline & & & $\operatorname{Pr}=0.7$ & \\
\hline & & & $t_{c h}=t_{f m}$ & \\
\hline & & & $\mathrm{L}_{\mathrm{ch}}=\mathrm{b}$ & \\
\hline \multirow{5}{*}{ Kitamura et al. [19] } & \multirow{5}{*}{ Equation (9) } & \multirow{4}{*}{$N u=0.6 \times R a_{q}^{0.2}$} & $\begin{array}{c}3 \times 10^{8}<R a_{q}< \\
2.5 \times 10^{10}\end{array}$ & \multirow{5}{*}{ quni } \\
\hline & & & $\operatorname{Pr}=6$ & \\
\hline & & & $t_{c h}=t_{f m}$ & \\
\hline & & & $\mathrm{L}_{\mathrm{ch}}=\mathrm{D}$ & \\
\hline & & $N u=0.23 \times R a^{* 0.24}$ & $\begin{array}{c}2.5 \times 10^{10}<R a_{q}< \\
3.6 \times 10^{10}\end{array}$ & \\
\hline \multirow{4}{*}{$\begin{array}{l}\text { Sadeghipour and } \\
\text { Razi [21] }\end{array}$} & \multirow{4}{*}{ Equation (10) } & \multirow{4}{*}{$\begin{array}{c}N u=Z \times R a^{0.188} \\
Z=\frac{1.251}{\eta^{\frac{1}{2}}} \times\left(1-e^{-1.236 \times 10^{-4} \eta^{3.5}}\right)+0.75 \text { and } \eta=\frac{W}{D} R a_{D}{ }^{0.27}\end{array}$} & $650 \leq R a \leq 1000$ & \multirow{4}{*}{$t_{\text {uni }}$} \\
\hline & & & $\operatorname{Pr}=0.7$ & \\
\hline & & & $t_{c h}=t_{f m}$ & \\
\hline & & & $\mathrm{L}_{\mathrm{ch}}=\mathrm{D}$ & \\
\hline \multirow{5}{*}{ Ashjaee et al. [23] } & \multirow{5}{*}{ Equation (11) } & \multirow{5}{*}{$\begin{array}{c}N u=B N u_{\infty} \\
N u_{\infty}=0.85 \times R a^{0.1888} 10^{2}<R a<10^{4} \\
N u_{\infty}=0.48 \times R a^{0.25} 10^{4}<R a<10^{7} \\
B=1-0.2357 \times \exp \left(-\left(\frac{\eta-0.8921}{0.9955}\right)^{2}\right) \\
\eta=\left(\left(\frac{H_{T}}{D}\right)^{1.215} \times R a^{0.141}-0.2\right)^{0.52}\end{array}$} & $10^{3} \leq R a \leq 4 \times 10^{4}$ & \multirow{5}{*}{$t_{\text {uni }}$} \\
\hline & & & $\operatorname{Pr}=0.7$ & \\
\hline & & & $t_{c h}=t_{f m}$ & \\
\hline & & & $\left.0.1 \leq H_{T} / D \leq 2.4\right)$ & \\
\hline & & & $\mathrm{L}_{\mathrm{ch}}=\mathrm{D}$ & \\
\hline & & & $10^{2} \leq R a \leq 10^{5}$ & \\
\hline & & $N u-K \times \quad R a_{D}^{0.375}$ & $0.1 \leq H_{B} / D \leq 1.7$ & \\
\hline Ashjaee et al. [29] & Equation (12) & $N u=K \times \frac{\left.\left(\ln a_{D}\right)\right)^{0.8}}{(\ln }$ & $\operatorname{Pr}=0.7$ & $t_{\text {uni }}$ \\
\hline & & $K=1.06+6.03 \times 10^{-3} \times\left(\frac{H_{B}}{D}\right)^{2.5}-0.392 \times e^{\left(\frac{-H_{B}}{D}\right)}$ & $t_{c h}=t_{f m}$ & \\
\hline & & & $\mathrm{L}_{\mathrm{ch}}=\mathrm{D}$ & \\
\hline & & $N u=0.55 \times R a_{q}^{0.248} \gamma^{0.158}\left\{1+0.0634 R a_{q}^{0.48} \operatorname{Pr}^{0.95} \gamma^{1.612}\right\}$ & $\begin{array}{c}6.1 \times 10^{4} \leq R a_{q} \leq \\
6.88 \times 10^{8}\end{array}$ & \\
\hline Abou-Ziyan et al. & Equation (13) & $\gamma-$ heat generation parameter & $30 \leq \operatorname{Pr} \leq 1850$ & quni \\
\hline & & $\gamma=\frac{q_{v}}{\left(T_{w}-T_{\infty}\right)}\left(D_{0}^{2}-D_{i}^{2}\right) /\left(k R a_{q}^{0.5} \operatorname{Pr}^{0.5}\right), q_{v}=\frac{4 V I}{\pi\left(D_{0}^{2}-D_{i}^{2}\right) L}$ & $\begin{array}{c}\mathrm{t}_{\text {char }}=\mathrm{t}_{\infty}+0.32\left(\mathrm{t}_{\mathrm{w}}-\right. \\
\left.\mathrm{t}_{\infty}\right)\end{array}$ & \\
\hline & & & $\mathrm{L}_{\text {char }}=\mathrm{D}$ & \\
\hline
\end{tabular}

Summarized in Table 1 are the recognized correlation equations and selected, recently published correlation equations, particularly those which relate Nusselt numbers to Rayleigh 
numbers and confinement ratios jointly. The correlation equations listed in Table 1 are evaluated in the next part of the paper with reference to new experimental data for water, EG, and a mixture of EG and water at $50 \% / 50 \%$ by volume.

Despite the numerous analytical, numerical and experimental studies regarding the container wall-heated cylinder interactions during free convection, knowledge of this process is still limited. Depending on the geometry-fluid combination of the thermal system the interactions tend to enhance or inhibit the cylinder heat transfer performance. Therefore, further studies, especially for different submersion depths—as stated in [34], are needed.

In present work results of free convection heat transfer performance from a uniformly heated horizontal tube are discussed. Tested fluids are ethylene glycol (EG), water (W), and a mixture of EG and water at 50/50 by volume. Geometry of the container is designed such that the generated motion of the fluid is not significantly affected by the free surface of the liquid, side walls (horizontal confinement), and bottom surface. In order to avoid influence of axial conduction on heat transferred from the cylinder, the length-to-diameter ratio was accordingly large. Experimentally obtained results in the form of predictions from developed correlation equations for selected Prandtl numbers are compared with predictions from recognized correlation equations for isolated cylinders as well as with recently developed correlation equations which relate Nusselt numbers to Rayleigh numbers and confinement ratios jointly.

\section{Experimental Setup}

\subsection{Experimental Apparatus}

The present experimental apparatus is schematically shown in Figure 1. The apparatus consisted of a test container, heated tube, electrical supply system, and PC-aided data acquisition system. The test container is made of acrylic glass (PMMA) with inner dimensions of $160 \mathrm{~mm} \times 160 \mathrm{~mm} \times 500 \mathrm{~mm}$ and wall thickness of $10 \mathrm{~mm}$. The container is thermally insulated with Styrodur. On the bottom of the container a discharge valve was installed.

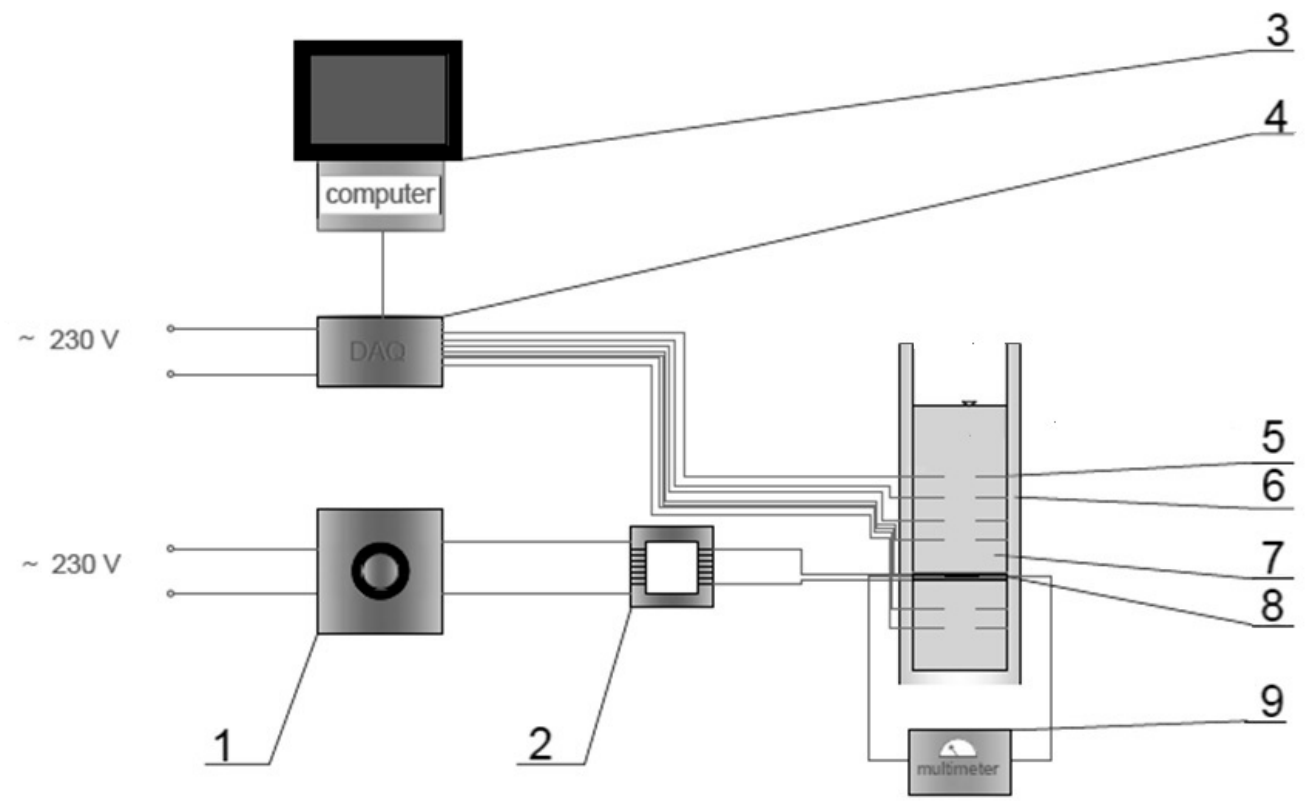

Figure 1. Scheme of the experimental setup: (1) variable transformer, (2) transformer, (3) PC-aided data acquisition system, (4) DAQ-module, (5) Pt100 resistance thermometers, (6) insulation, (7) test vessel, (8) heating section (9) multimeter.

The submersion depth of the heated tube was established as $\mathrm{H}_{\mathrm{T}}=205 \mathrm{~mm}$-Figure 2, so the dimensionless liquid depth was equal to $\mathrm{H}_{\mathrm{T}} / \mathrm{D}=20.5$. According to the literature 
announcements the free convection heat transfer around horizontal cylinders is not affected by liquid surface for dimensionless liquid depths above $\mathrm{H}_{\mathrm{T}} / \mathrm{D}>3[22,36,37]$. The bottom periphery of the tube was located $\mathrm{H}_{\mathrm{B}}=135 \mathrm{~mm}$ above the horizontal base plate, so the dimensionless bottom to cylinder distance was $\mathrm{H}_{\mathrm{B}} / \mathrm{D}=13.5$-large enough to neglect bottom wall influence on free convection heat transfer from a horizontal cylinder $[19,37]$. The distance between the vertical walls of the container and the lateral periphery of the tube was $S_{W}=75 \mathrm{~mm}$, so the dimensionless distance, $S_{W} / D=7.5$, was large enough to neglect influence of horizontal confinement on free convection heat transfer from the horizontal cylinder $[14,22,37]$.
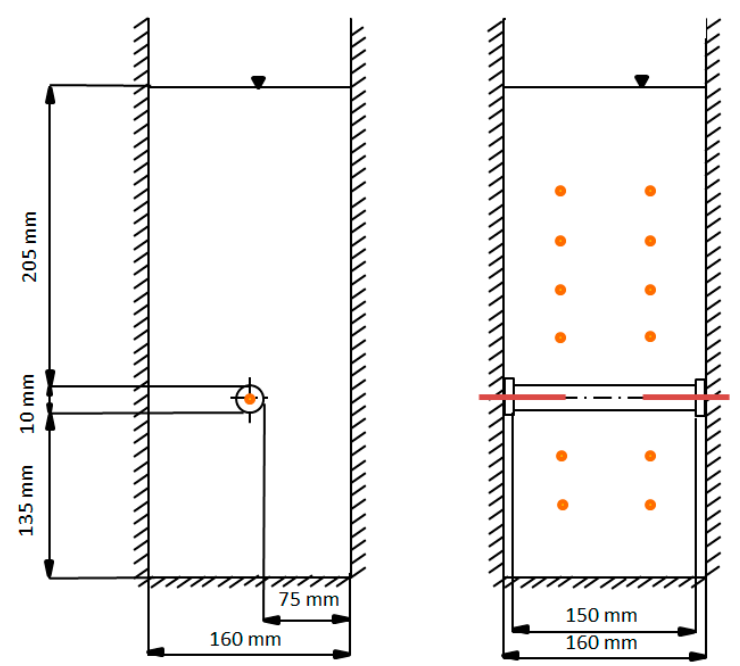

Figure 2. Scheme of the experimental container.

Liquid temperature inside the container was measured by use of twelve resistance thermometers type Pt100 placed in pairs at various levels Figure 2. The resistance thermometers were produced by TC Direct (Mönchengladbach, Germany). The tolerance class of the resistance thermometers is B following the European standard DIN EN 60751 $( \pm 0.05 \mathrm{~K}+ \pm 0.3 \mathrm{~K}= \pm 0.35 \mathrm{~K})$.

Commercially available stainless steel tube having $10 \mathrm{~mm}$ OD and $0.6 \mathrm{~mm}$ wall thickness was used to fabricate the test heater. The effective length of the tube was $\mathrm{L}=150 \mathrm{~mm}$. The length of the tube was $\mathrm{L}=15 \mathrm{D}$, large enough to assume generated flows as $2 \mathrm{D}[7,14,36,38]$. The ends of the tube were soldered to copper joints in order to minimize any additional electrical resistance. The experiment was conducted under constant heat flux boundary condition $\mathrm{q}=$ const., by using the tube itself as a resistance heater. The power supply was adjusted by an electrical transformer. The inside temperature of the test tube was measured using two resistance thermometers Pt100 placed on the centre line of the tube-Figure 3.

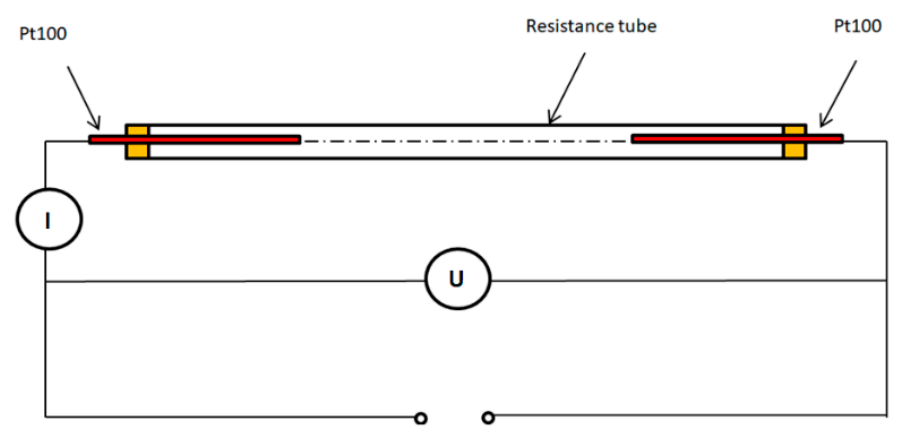

Figure 3. Scheme of the heated cylinder. 
Power supply was adjusted by two electrical transformers. A variable transformer was connected directly to the 2-phase electrical socket and transformed the voltage from $230 \mathrm{~V}$ by the frequency of $50 \mathrm{~Hz}$ to the output voltage ranging from 0 to $240 \mathrm{~V}$. The second transformer reaches the expected electrical parameters of the heating section of maximal $1 \mathrm{~V}$ and $200 \mathrm{~A}$ and has a power rating of $200 \mathrm{VA}$. The data recording was possible with the usage of a Texas Instruments DAQ-module, which collected all the measured electrical and thermal parameters measured during the experiment. The registration and visualization of the measured parameters was executed by the LabVIEW 2015 system (National Instruments, Austin, TX, USA).

Tested fluids were ethylene glycol, water and a mixture of EG-water $(50 \% / 50 \%)$ by volume. Viscosity of the tested liquids was measured by use of the viscometer Rheotest LK 2.2 of Rheotest Medingen GmbH (Medingen, Germany) coupled with an Alpha A6 thermostat (Lauda-Brinkmann, Lauda-Königshofen, Germany). A capillary for viscosity range from 1 to $16 \mathrm{mPas}$ was used. As the viscosity of the liquids exhibits nonlinear behaviour the measurement data were correlated by use of the exponent functions (Table 2).

Table 2. Correlations for the dynamic viscosity of the tested fluids.

\begin{tabular}{ccc}
\hline Liquid & Present Correlation & Equation Number \\
\hline Water & $\mu_{f}=1.435 \times 10^{-5} \times e^{\frac{1227}{T}}$ & Equation (14) \\
\hline EG & $\mu_{f}=1.6 \times 10^{-7} \times e^{\frac{3440}{T}}$ & Equation (15) \\
\hline Water/EG (50:50) & $\mu_{f}=2.81 \times 10^{-7} \times e^{\frac{2748}{T}}$ & Equation (16) \\
\hline
\end{tabular}

A KD2 Thermal Properties Analyser from Decagon Devices Inc. (Pullman, WA, USA) was used to determine thermal conductivity of the tested liquids. The implemented sensor enabled measurement of the thermal conductivity within the range from 0.02 to $2.00 \mathrm{~W} /(\mathrm{mK})$ with maximum uncertainty of $\pm 5 \%$.

Because of weak dependence on temperature, measured values of the thermal conductivity of the tested liquids were correlated by use of the linear functions (Table 3).

Table 3. Correlations for the thermal conductivity of the base fluids.

\begin{tabular}{ccc}
\hline Liquid & Correlation & Equation Number \\
\hline Water & $k_{f}=1.974 \times 10^{-3} \times T$ & Equation (17) \\
\hline EG & $k_{f}=8.49 \times 10^{-4} \times T$ & Equation (18) \\
\hline Water/EG (50:50) & $k_{f}=1.334 \times 10^{-3} \times T$ & Equation (19) \\
\hline
\end{tabular}

The other properties of the tested liquids were obtained from the data provided in the ASHRAE Handbook [39] and were curve-fitted as a function of the temperature with the equations shown in Table 4.

Table 4. Correlations for determination of properties of the tested liquids.

\begin{tabular}{cccc}
\hline Liquid & $\rho\left[\mathbf{k g} / \mathbf{m}^{3}\right]$ & $\mathbf{c}_{\mathbf{p}}[\mathbf{J} / \mathbf{( k g K ) ]}$ & $\boldsymbol{\beta}[\mathbf{1} / \mathbf{K}]$ \\
\hline Water & $\rho=1107.6-0.3708 \times T$ & $c_{p}=5603-9.2129 \times T+0.0149 \times T^{2}$ & $\beta=-0.0076+4.36 \times 10^{-5} \times T-5.73 \times 10^{-8} \times T^{2}$ \\
\hline EG & $\rho=1331.2-0.732 \times T$ & $c_{p}=1062.3+4.507 \times T$ & $\beta=0.65 \times 10^{-3}$ \\
\hline Mixture W/EG (50/50) by vol. & $\rho=1215.1-0.4842 \times T$ & $c_{p}=2150.7+3.8567 \times T$ & $\beta=-0.003+1.83 \times 10^{-5} \times T-2.25 \times 10^{-8} \times T^{2}$ \\
\hline
\end{tabular}

The fluid properties of the tested liquids were evaluated at the mean film temperature. For this temperature Prandtl numbers ranged from $5 \leq \operatorname{Pr} \leq 160$, Rayleigh numbers varied within the range $5 \times 10^{4} \leq \mathrm{Ra} \leq 7 \times 10^{5}$, and Rayleigh numbers based on heat flux, $\mathrm{q}$, changed within the range $4.5 \times 10^{6} \leq \mathrm{Ra}_{\mathrm{q}} \leq 10^{7}$. 


\subsection{Experimental Procedure}

Before each measurement the stand of the experimental setup was thoroughly checked. The cubical container was cleaned with water and dried before filling with the tested fluid. The check of the measurement apparatus was done for the installed thermometers and electrical devices. During the experiment the inside tube temperature, the distribution temperature of the fluid inside of the cubical container in twelve locations, the voltage and current were measured and registered with LabVIEW 2015 software. This data was recorded during established quasi-steady states. Initially, fluids in the experimental container reached steady state after about two hours. Steady state was assumed to have been reached when the temperature difference between the tube's wall and liquid was less than $0.1 \mathrm{~K}-[40,41]$. It took about $15-20 \mathrm{~min}$ to achieve steady state condition. A new steady state was reached by increasing the voltage and current to the heating section, regulated with a variable transformer. The analysis of the free convective heat transfer from a horizontal cylinder was conducted for the power range varying from 0 to $120 \mathrm{~W}$ $(0<\mathrm{q}<20) \mathrm{kW} / \mathrm{m}^{2}$.

\subsection{Data Reduction and Measurement Error}

Heat flux was calculated from the electrical parameters measured during the experiment and geometry of the cylinder:

$$
q=\frac{P_{e l}-\dot{Q}_{l o s}}{\pi D_{o} L}=\frac{0.9 P_{e l}}{\pi D_{o} L}=\frac{0.9 U_{e l} I_{e l}}{\pi D_{o} L}
$$

where: $\dot{Q}_{l o s}[\mathrm{~W}]$ - heat loss flow rate from the heating section through the cabling and wiring estimated to be $10 \%$ of electrical power supplied.

The inside temperature of the tube was calculated as an arithmetic mean of the measured two inside temperatures with Pt100 thermometers (Figure 3):

$$
t_{i n}=\frac{t_{i n, 1}+t_{i n, 2}}{2}
$$

Mean temperature of the outside surface of the tube was determined from following equation [42]:

$$
t_{w}=t_{\text {in }}-U_{e l} I_{e l} \frac{\ln \left(D_{o} / D_{\text {in }}\right)}{2 \pi k L}
$$

The wall-to-fluid temperature difference was estimated as:

$$
\Delta T=t_{w}-t_{f}
$$

The fluid's temperature is measured in twelve different locations in the fluid containerfour below the horizontal cylinder and eight above. For the calculation of the mean fluid temperature $t_{f}$, only the measurement taken above the cylinder has been assumed, as the presence of the free convective heat transfer below the heating section was negligible. Therefore, the mean fluid temperature was calculated as the arithmetic mean of the eight fluid temperatures:

$$
t_{f}=\frac{\sum_{i=1}^{i=8} t_{f, i}}{8}
$$

The accuracy of calculated parameters is estimated with the mean square method. The uncertainty of the heat flux was estimated as follows:

$$
\Delta q=\sqrt{\left(\frac{\partial q}{\partial P_{e l}} \Delta P_{e l}\right)^{2}+\left(\frac{\partial q}{\partial D_{o}} \Delta D_{o}\right)^{2}+\left(\frac{\partial q}{\partial L} \Delta L\right)^{2}}
$$


The approximate measurement errors of the electrical power $\Delta P_{e l}$, outside tube diameter $\Delta D_{o}$ and active length of the tube $\Delta L$ are $1 \mathrm{~W}, 0.1 \mathrm{~mm}$, and $0.5 \mathrm{~mm}$, respectively. The maximum approximation error for the heat flux was estimated to be $\pm 1.2 \%$

\section{Results}

Present experimental results were correlated presenting $\mathrm{Nu}$ number as a function of Ra and Pr numbers. Cylinder diameter $D$ and boundary layer length $b$ commonly taken as the characteristic lengths for free convection in an unbounded medium are employed in the developed correlation equations. The present experiment was conducted with constant heat flux, therefore the Rayleigh numbers are based not only on temperature difference but on heat flux too. In order to elaborate Nusselt-type correlations regression analysis based on the least squares method was implemented. In Table 5 are summarized the presently developed empirical correlations.

Table 5. The developed empirical heat transfer correlations for a horizontal cylinder.

\begin{tabular}{|c|c|c|c|c|c|}
\hline Liquid & $\begin{array}{l}\text { Equation } \\
\text { Number }\end{array}$ & Relationship & Ra Range & Pr Range & $\begin{array}{c}\text { Data within 5\% } \\
\text { Equation }\end{array}$ \\
\hline \multirow{3}{*}{ Water } & Equation (26) & $N u=0.374 \operatorname{Ra}^{0.2613} \operatorname{Pr}^{0.16}$ & $5.2 \times 10^{4}<\mathrm{Ra}<5.1 \times 10^{5}$ & \multirow{3}{*}{$4.5<\operatorname{Pr}<7$} & $88 \%$ \\
\hline & Equation (27) & $N u=0.4017 R a_{q}^{0.2109} P r^{0.166}$ & $4.7 \times 10^{5}<\mathrm{Ra}_{\mathrm{q}}<9 \times 10^{6}$ & & $92 \%$ \\
\hline & Equation (28) & $N u_{b}=0.4153 R a_{b}^{0.2609} \operatorname{Pr}^{0.159}$ & $2 \times 10^{5}<\mathrm{Ra}_{\mathrm{b}}<2 \times 10^{6}$ & & $88 \%$ \\
\hline \multirow{3}{*}{ EG } & Equation (29) & $N u=0.4673 \mathrm{Ra}^{0.231} \mathrm{Pr}^{0.096}$ & $3.6 \times 10^{4}<\mathrm{Ra}<6.7 \times 10^{5}$ & \multirow{3}{*}{$45<\operatorname{Pr}<160$} & $64 \%$ \\
\hline & Equation (30) & $N u=0.1543 \operatorname{Ra}_{q}^{0.235} \operatorname{Pr}^{0.203}$ & $3.6 \times 10^{5}<\operatorname{Ra}_{\mathrm{q}}<10.3 \times 10^{6}$ & & $72 \%$ \\
\hline & Equation (31) & $N u_{b}=0.624 R a_{b}^{0.2245} \operatorname{Pr}^{0.081}$ & $1.4 \times 10^{5}<\mathrm{Ra}_{\mathrm{b}}<2.6 \times 10^{6}$ & & $64 \%$ \\
\hline \multirow{3}{*}{$\begin{array}{l}\text { W/EG } \\
(50: 50)\end{array}$} & Equation (32) & $N u=1.7053 R a^{0.1626}$ & $6.8 \times 10^{4}<\mathrm{Ra}<9.2 \times 10^{5}$ & \multirow{3}{*}{$10<\operatorname{Pr}<25$} & $100 \%$ \\
\hline & Equation (33) & $N u=1.5785 R a_{q}^{0.14}$ & $7.3 \times 10^{5}<\operatorname{Ra}_{\mathrm{q}}<14.8 \times 10^{6}$ & & $100 \%$ \\
\hline & Equation (34) & $N u_{b}=2.1465 R a_{b}^{0.1627}$ & $2.7 \times 10^{5}<\mathrm{Ra}_{\mathrm{b}}<3.6 \times 10^{6}$ & & $100 \%$ \\
\hline \multirow{3}{*}{ All } & Equation (35) & $N u=0.9985 R a^{0.2034} P^{0.001}$ & $3.6 \times 10^{4}<\mathrm{Ra}<9.2 \times 10^{5}$ & \multirow{3}{*}{$4.5<\operatorname{Pr}<160$} & $72 \%$ \\
\hline & Equation (36) & $N u=0.9593 R a_{q}^{0.1709} P r^{0.004}$ & $3.6 \times 10^{5}<\operatorname{Ra}_{\mathrm{q}}<14.8 \times 10^{6}$ & & $76 \%$ \\
\hline & Equation (37) & $N u_{b}=1.2092 R a_{b}^{0.2023} \operatorname{Pr}^{0.001}$ & $1.4 \times 10^{5}<\mathrm{Ra}_{\mathrm{b}}<3.6 \times 10^{6}$ & & $72 \%$ \\
\hline
\end{tabular}

As an example Figure 4 shows experimental results for water with Nusselt number estimation with Equations (27) and (36) dedicated only for water and all three tested liquids, respectively. As results from Table 5, 92\% of experimental points are within $\pm 5 \%$ band fixed by correlation equation (Equation (27)). Therefore, the repeatability of the results obtained during successive measurements may be recognized as satisfactory.

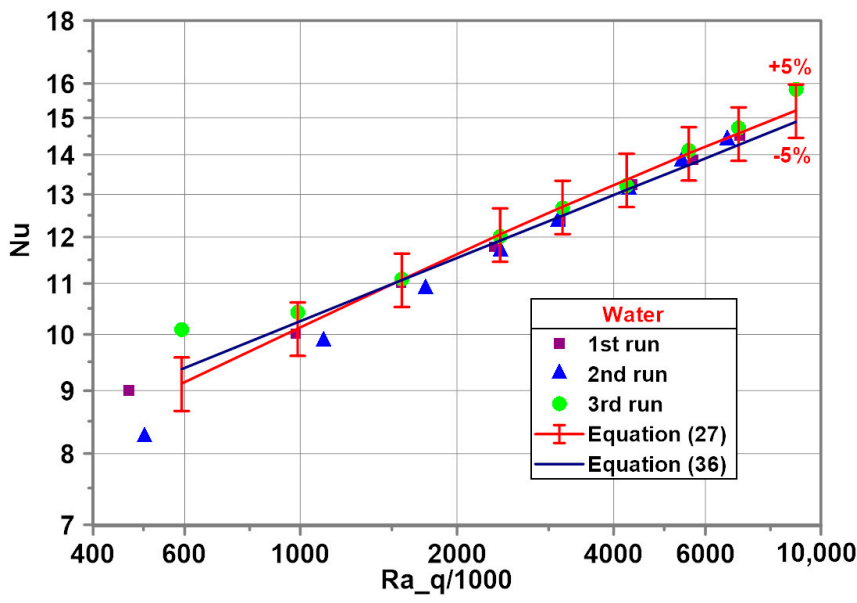

Figure 4. Experimental vs. predicted values of $\mathrm{Nu}$ number. 
In the following section the predictions of the average Nusselt numbers obtained from the developed empirical correlation equations presented in Table 5 are compared with predictions from the recognized literature correlation equations shown in Table 1.

In Figure 5 the predictions of the average Nusselt numbers for three tested liquids, i.e., water, EG, and a water/EG (50:50) mixture are compared to the predictions made by commonly used correlation equations for isolated cylinders $[2,4,6,7,10]$ - see Table 1. Selected literature correlation equations are based on the same characteristic length (cylinder diameter), the same characteristic temperature (mean film temperature), and the Rayleigh number related to the mean temperature difference. However, except for the Churchill and Chu correlation-Equation (1a) in Table 1, recommended for uniform heating as well as for uniform surface temperature, four other correlation equations (Equations (2), (3), (4c) and (5)) are recommended only for uniform surface temperature condition. The general trends of the predictions obtained by use of the literature correlation equations and the predictions from developed correlation equations are the same for all three tested liquids. However, distinct discrepancies are seen for particular liquids. For water (Figure 5a) all literature correlation equations (Equations (1a)-(5)) underestimate the average Nusselt number compared to the predictions from the present empirical correlation equation (Equation (26)). The best match with the predictions from Equation (26) is the correlation equation proposed by Churchill and $\mathrm{Chu}$ (Equation (1a)), with a maximum deviation of about $6.3 \%$ for the minimum Ra number. The biggest discrepancy is found in the correlation equation proposed by Morgan (Equation (2)), with about 14.7\% deviation for the maximum Ra number.

A different case is observed for pure EG (Figure 5b). For the minimum Ra number, except for the Fand and Brucker correlation equation (Equation (5)), other correlation equations (Equations (1a), (2), (3) and (4c)) underestimate the predictions from Equation (29) with a maximum deviation of $19 \%$ (Equation (2)). For the maximum Ra number tested, correlations proposed by Churchill and Chu (Equation (1a)) and Fand et al. (Equation (4c)) overestimate the predictions from Equation (29) by about $8 \%$ and $4.8 \%$, respectively. The correlation equation proposed by Kuehn and Goldstein (Equation (3)) reproduces the present experimental data quite well with an average deviation of about $3 \%$.

For the water/EG (50:50) mixture (Figure $5 c$ ) all correlation equations from literature (Equations (1a), (2), (3), (4c) and (5)) underestimate predictions from Equation (32) for the minimum Ra number with a maximum deviation of $25.9 \%$ (Equation (2)) and overestimate predictions from Equation (32) for the maximum Ra number with a maximum deviation of 14.3\% (Equation (1a)). The correlation proposed by Fand and Brucker (Equation (5)), shows adequate compatibility with predictions from Equation (32), particularly for Ra numbers above $5 \times 10^{5}$-in this region discrepancy does not exceed $3.8 \%$.

Among tested correlations (Equations (1a)-(5)) only Equation (5) takes into account viscous dissipation. Good agreement of the predictions obtained from use of Equation (5) with the data for EG may suggest that viscous dissipation is of significant importance under free convection heat transfer of fluids with a higher Pr number.

As mentioned above, the present experiment was conducted under constant heat flux condition by using the tube itself as a resistance heater. Therefore, the correlation equations recommended for uniform heating of the horizontal cylinders (Equations (1b), (9) and (13)) are compared with present experimental data. It is noteworthy to say that the Rayleigh number is, in this case, based on heat flux instead of a mean temperature difference. As it is seen in Figure 6a, correlations proposed by Churchill and Chu (Equation (1b)) and Kitamura et al. (Equation (9)) slightly underestimate predictions from the developed correlation (Equation (27)) with a maximum deviation of $3.4 \%$ and $5.4 \%$, respectively. The experimentally developed correlation proposed by Abou-Ziyan et al. (Equation (13)) overestimates predictions from the developed Equation (27) by about $22 \%$. Two factors may explain possible heat transfer enhancement during experiments of Abou-Ziyan et al. [32], in comparison to the present data. First, the small aspect ratio of the tested cylinder $(\mathrm{L} / \mathrm{D}=8)$, while $\mathrm{L} / \mathrm{D}>15$ is treated as large enough to assume a cylinder as infi- 
nite $[11,22,29]$. Second, application of the electrical heater below the tested cylinder could potentially induce buoyant plume impinging on the heated cylinder, and as a result improve heat transfer.

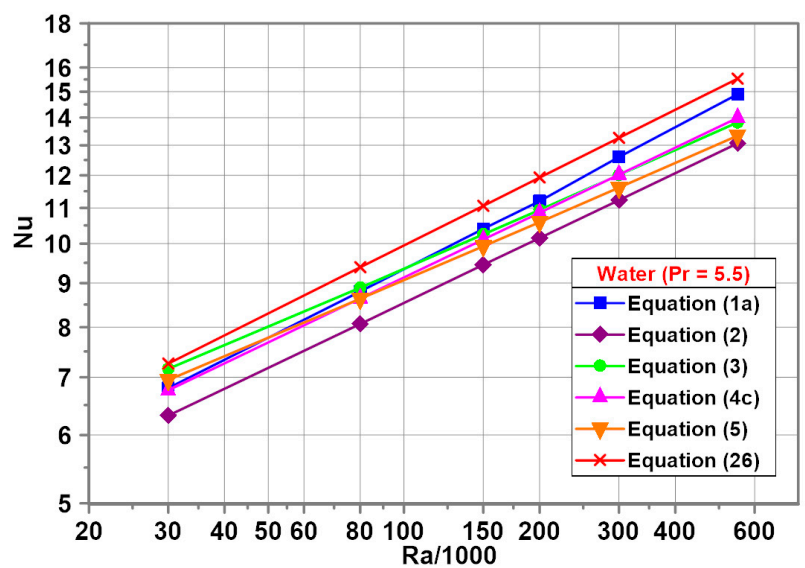

(a)

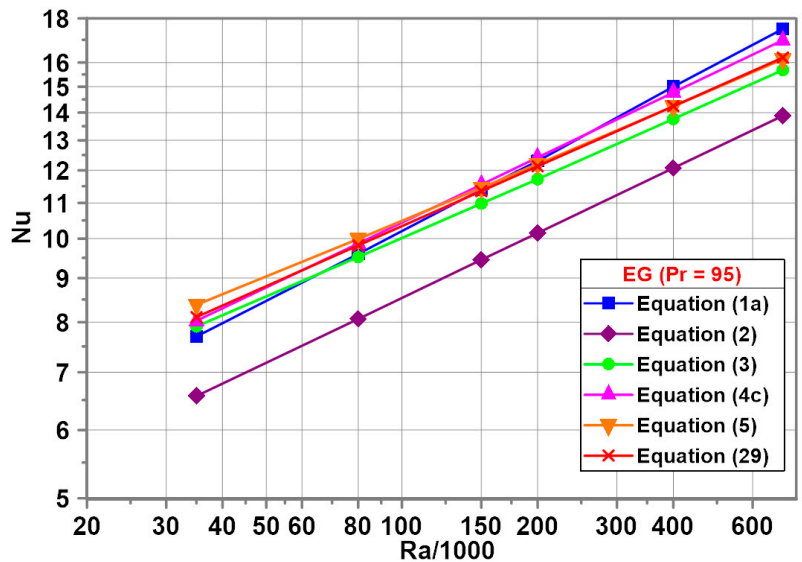

(b)

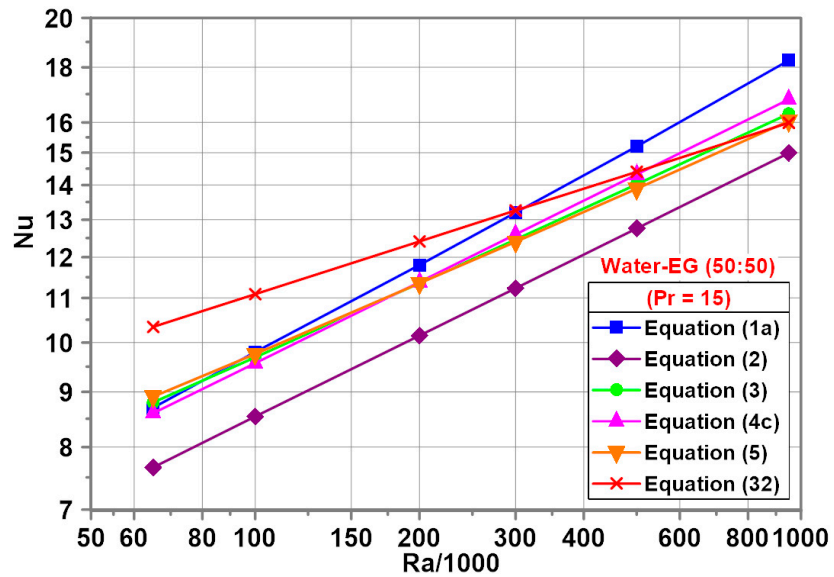

(c)

Figure 5. Present Nu-Ra relationship vs. predictions from literature correlations for water (a), EG (b), and water-EG (50:50) (c) The best match with the predictions from Equation (29) is shown to be the correlation equation proposed by Fand and Brucker (Equation (5)) with an average deviation of about $\pm 1.2 \%$. The biggest discrepancy is found in the correlation equation proposed by Morgan (Equation (2)), with about $19 \%$ deviation for the minimum Ra number. 


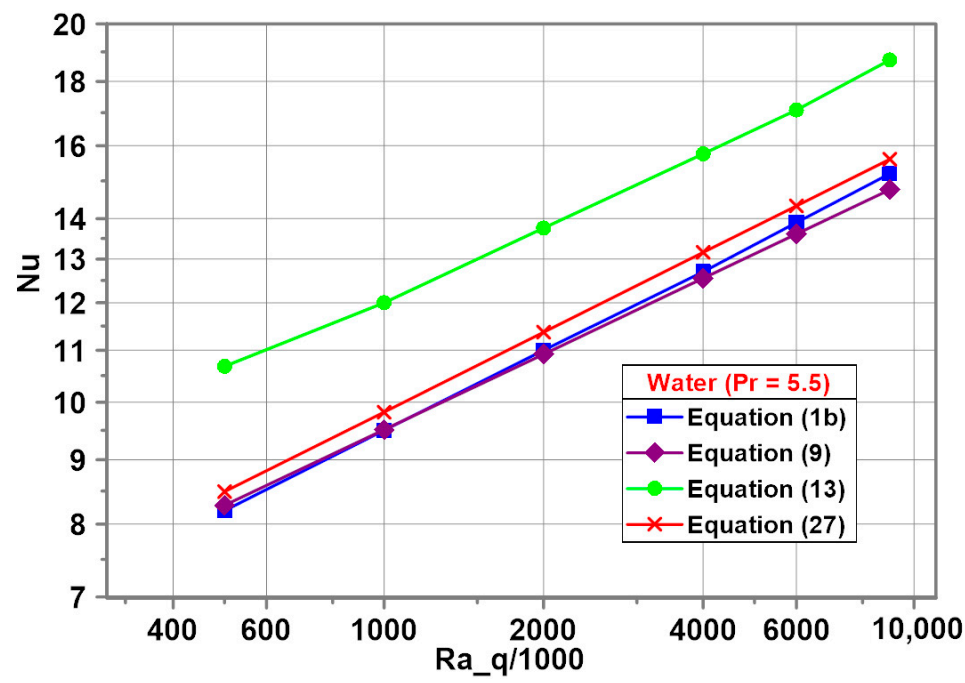

(a)

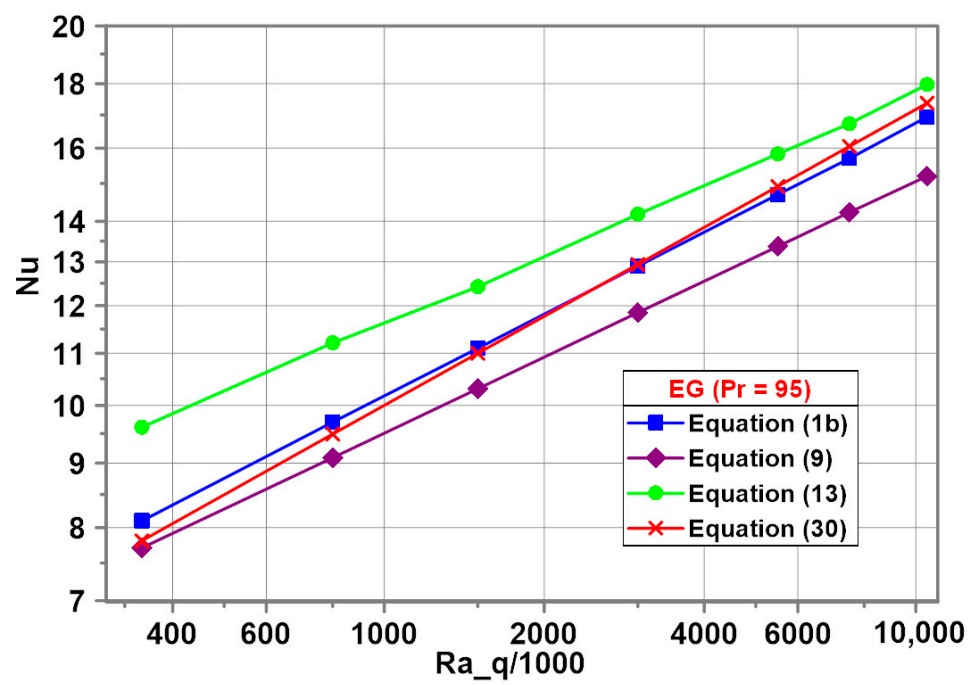

(b)

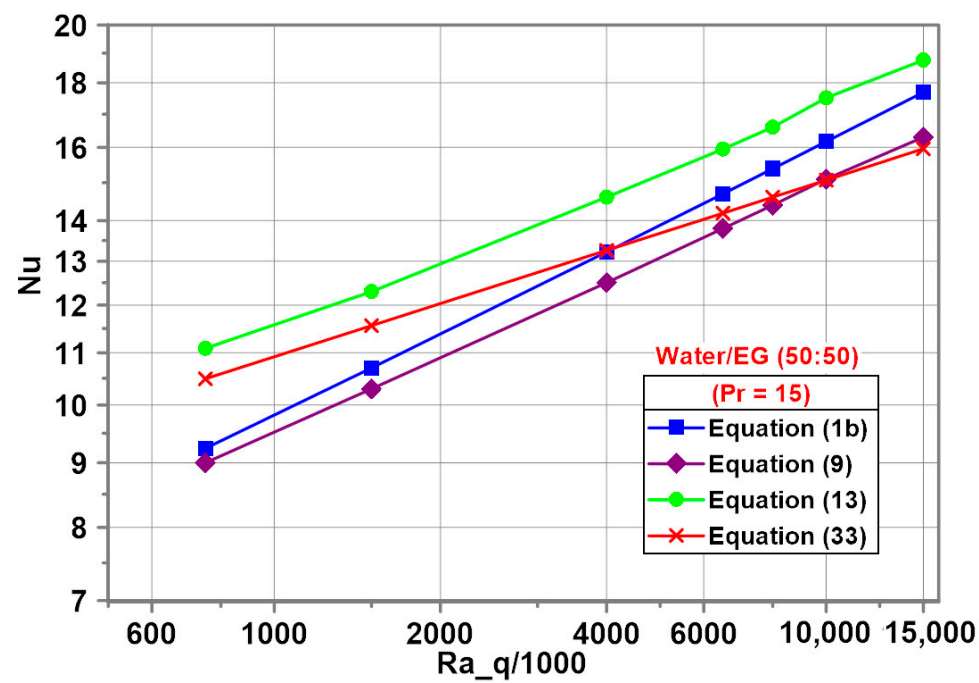

(c)

Figure 6. Present $\mathrm{Nu}-\mathrm{Ra}_{\mathrm{q}}$ relationship vs. predictions from literature correlations for water (a), EG (b), and water-EG (50:50) (c). 
Present experimental data for EG (Figure $6 \mathrm{~b}$ ) are reasonably reproduced by the Churchill and Chu correlation (Equation (1b)). Predictions from the developed Equation (33) are overestimated for the minimum Ra number by about $3.7 \%$, and underestimated for the maximum Ra number by about $2.5 \%$. The Kitamura et al. correlation (Equation (9)) underestimates predictions from Equation (30) within the whole range of Ra numbers with maximum difference of $1.3 \%$ for the minimum Ra number and $12.5 \%$ for the maximum Ra number. Again, the Abou-Ziyan et al. correlation (Equation (13)) overestimates predictions from the developed Equation (30) within the whole range of Ra numbers with a difference of $23 \%$ for the minimum Ra number and $3.5 \%$ for the maximum Ra number.

For the water/EG (50:50) mixture (Figure 6c) only the Abou-Ziyan et al. correlation (Equation (13)) overestimates predictions from the developed Equation (33) within the whole range of Ra numbers with a difference of $5.7 \%$ for the minimum Ra number and $17.5 \%$ for the maximum Ra number.

The Churchill and Chu correlation (Equation (1b)) and Kitamura et al. correlation (Equation (9)) underestimate predictions from the developed Equation (33) for the minimum Ra number by about $11.9 \%$ and $14.2 \%$ respectively, and overestimate for the maximum Ra number by about $11 \%$ and $23 \%$ respectively.

In the literature other characteristic lengths for isolated cylinders than their diameter are proposed. For instance, Lienhard [43] proposed the half circumference of a cylinder as a characteristic length for an isothermal cylinder immersed in an infinite fluid ( $b=\pi \mathrm{D} / 2)$. In Figure 7 predictions of the Nusselt number for water obtained by use of the developed Equation (28) are compared with predictions from correlation equations proposed by Warrington and Powe (Equation (6b)) and Ghaddar (Equation (8b)) with boundary layer length $b$ as a characteristic length.

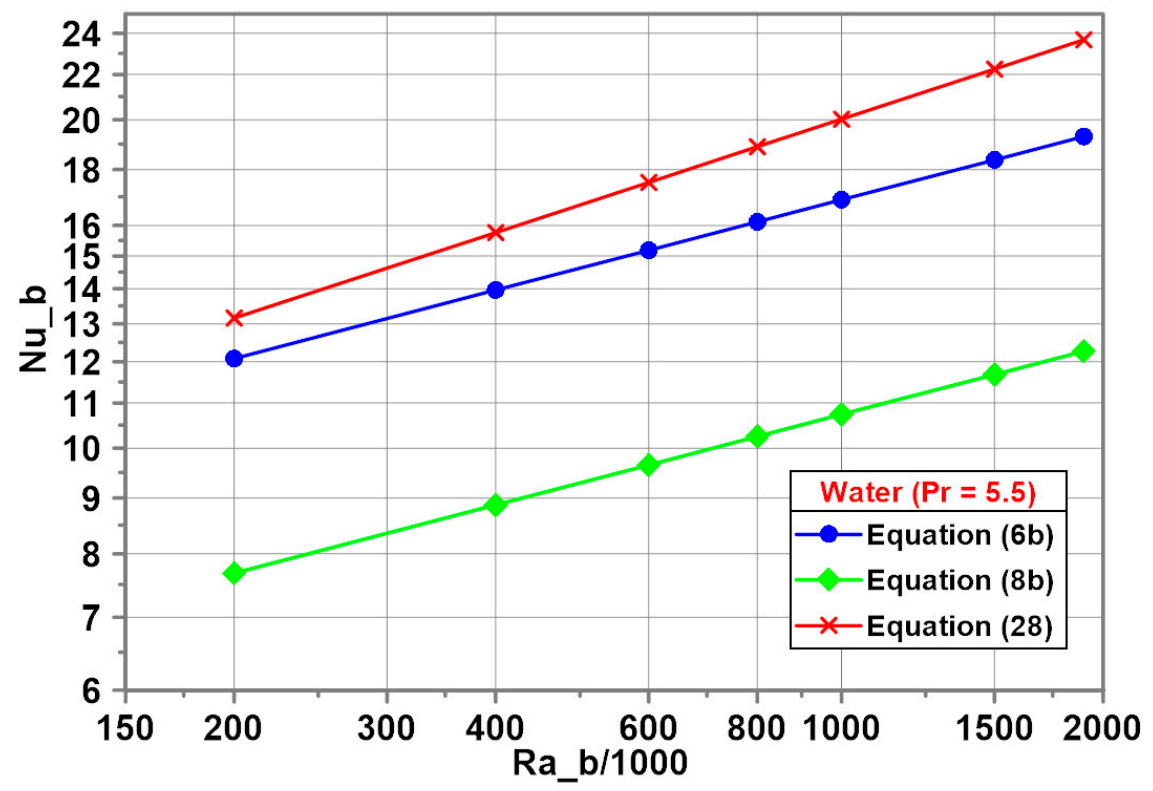

Figure 7. Present $\mathrm{Nu}-\mathrm{Ra}_{\mathrm{b}}$ relationship vs. predictions from literature correlations.

Despite the fact, that the Warrington and Powe empirical correlation (Equation (6b)) has been developed for enclosures with small aspect ratios $(0.51 \leq \mathrm{L} / \mathrm{D} \leq 0.86)$, it reasonably reproduced predictions from the present correlation (Equation (28)). The underprediction is equal to $8.2 \%$ for the minimum Ra number and $18.5 \%$ for the maximum Ra number. The Ghaddar correlation (Equation (8b)) underestimates the predictions from the developed correlation (Equation (28)) with a maximum deviation of $48 \%$ for the maximum Ra number. The big discrepancy may result from the fact that Ghaddar's correlation has been developed for a fluid of lower Pr number, i.e., air $(\operatorname{Pr}=0.72)$ and a smaller aspect ratio $(\mathrm{L} / \mathrm{D}=10)$. 
Recently, the question of the influence of heated body submersion depth $\mathrm{H}_{\mathrm{T}}$ on heat transfer was studied by several investigators $[18,23,25,28]$. In literature, however, the number of correlations that include explicitly submersion depth in the Nu-Ra relationship is very limited. In Figure 8, predictions from the developed correlation (Equation (26)) are compared to predictions made from the correlation equation proposed by Ashjaee et al. (Equation (11)) for relative cylinder submersion depth equal to $\mathrm{H}_{\mathrm{T}} / \mathrm{D}=20.5$. As seen in Figure 8, the Ashjaee et al. correlation (Equation (11)) underestimates predictions from Equation (26) by about $14.6 \%$. The discrepancy, although insignificant, can be explained by two factors. First, different thermal conditions upon which correlations are based: an isothermal surface in the Ashjaee et al. case and constant heat flux on the surface of the cylinder in the present study. Second, the Ashjaee et al. correlation has been developed for air $(\operatorname{Pr}=0.7)$, while the present correlation is for water.

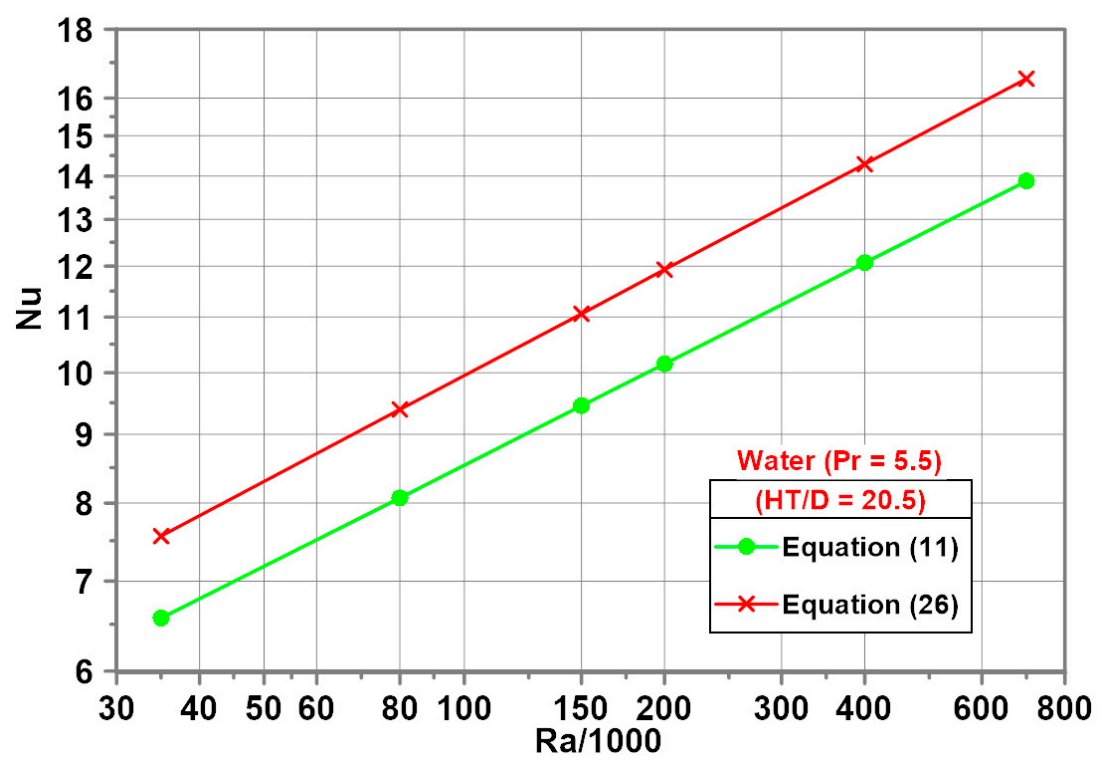

Figure 8. Present Nu-Ra relationship vs. predictions from literature correlation which relates Nusselt number to Rayleigh number and dimensionless submersion depth.

The influence of distance between a heated body and vertical walls $S_{W}$ on heat transfer was studied in $[14,21]$. Figure 9 compares predictions from the developed correlation Equation (29) against predictions obtained by use of the Karim et al. correlation (Equation (7)) and the Sadeghipour and Razi correlation (Equation (10)). As seen in Figure 9, the correlation proposed by Karim et al. (Equation (7)) gives results comparable to the present correlation (Equation (29)), although the underestimation is about $18.4 \%$ for the minimum Ra number. The Sadeghipour and Razi (Equation (10)) correlation, on the other hand, distinctly underestimates predictions from the developed correlation (Equation (29)) with a maximum difference of about $38 \%$ for the maximum Ra number. The deviation may be explained by the extremely low Ra number range for which the Sadeghipour and Razi (Equation (10)) correlation has been developed (Table 1). 


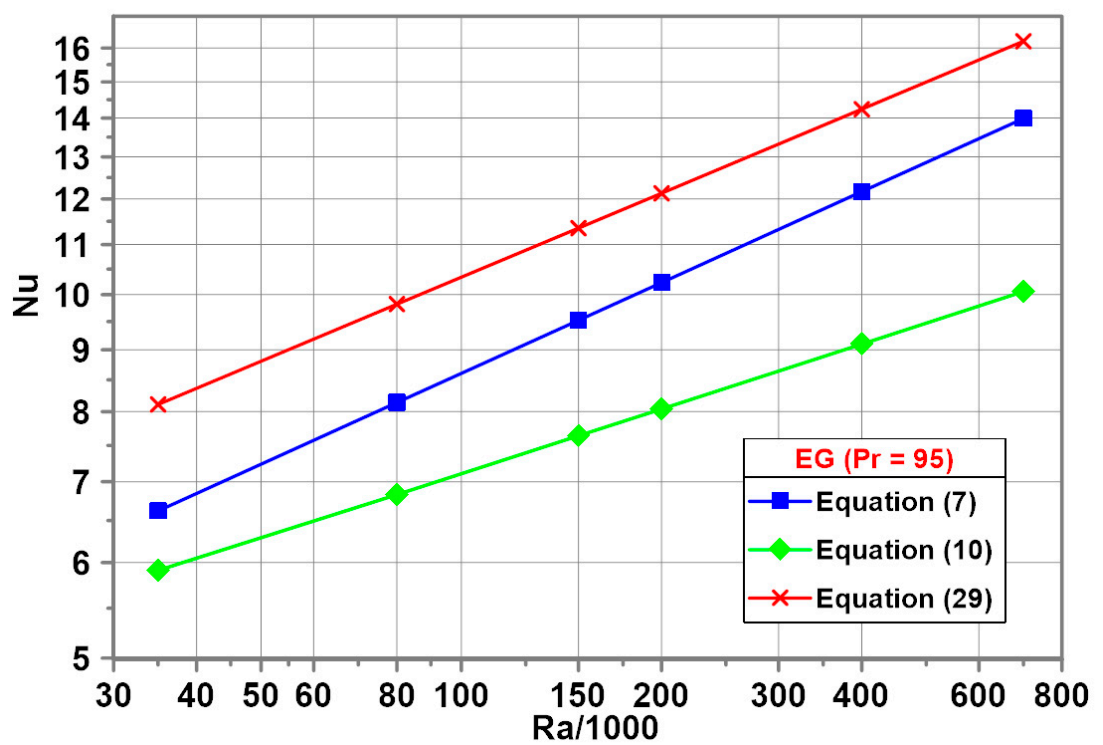

Figure 9. Present Nu-Ra relationship vs. predictions from literature correlations which relate Nusselt number to Rayleigh number and dimensionless vertical wall spacing.

Only a limited number of correlation equations that jointly describe the dependence of the Nusselt number vs. Rayleigh number and confinement ratio $\mathrm{H}_{\mathrm{B}} / \mathrm{D}$ is published. In Figure 10, predictions from the developed correlation (Equation (32)) for water/EG mixture are compared with predictions obtained by use of the correlation equation proposed by Ashjaee et al. (Equation (12)). As seen in Figure 10, the Ashjaee et al. correlation (Equation (12)) repeatedly gives higher values of $\mathrm{Nu}$ numbers than the present correlation. The deviation may be explained by the extremely low $\mathrm{H}_{\mathrm{B}} / \mathrm{D}$ ratio range $\left(0.1 \leq H_{B} / D \leq 1.7\right)$ for which the Ashjaee et al. correlation has been developed.

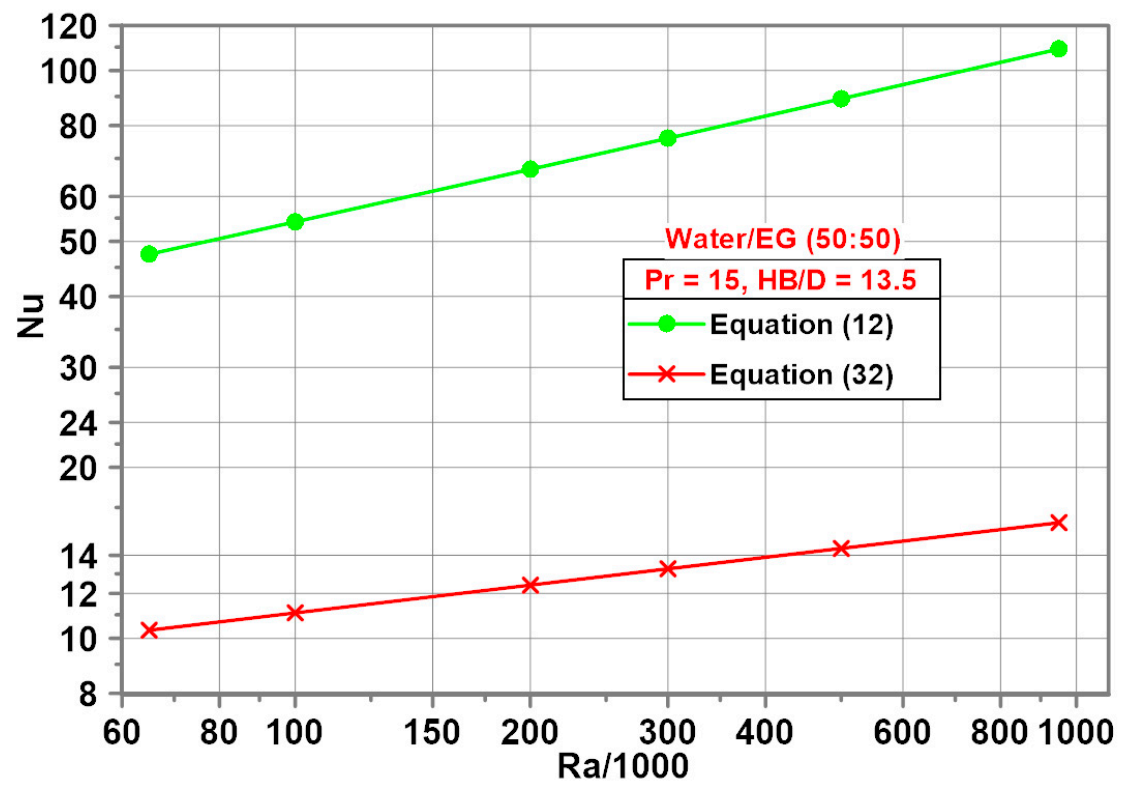

Figure 10. Present Nu-Ra relationship vs. predictions from literature correlation which relates Nusselt number to Rayleigh number and dimensionless bottom wall spacing.

Fand et al. [7] discussed the problem of the optimum characteristic temperature for which the thermophysical properties of fluids should be determined. Figure 11 compares predictions of the Nusselt numbers from developed correlations for water 
(Equation (26)) and EG (Equation (29)) with estimations from the Fand's et al. correlations (Equation $(4 \mathrm{a}-\mathrm{c}))$, based on different methods of characteristic temperature determination (Table 1). As seen in Figure 11a, the Fand's et al. correlations underestimate the Nusselt numbers determined from present empirical correlations for water with a maximum difference of about $8 \%$ for the minimum Ra number. For EG, the Fand's et al. correlations slightly underestimate the Nusselt numbers for lower Ra numbers and overestimate the Nusselt numbers determined from present empirical correlations with a maximum difference of about $6.7 \%$. The discrepancy can be explained by the fact, that the Fand's et al. correlations have been developed for fluid of low Prandtl number $(\operatorname{Pr}=0.7)$, while the present correlations are developed for liquids with much higher Prandtl numbers $(4.5<$ $\operatorname{Pr}<160$ ). Important to note is, that the form of the characteristic temperature for which the thermophysical properties of the tested fluids have been determined has negligible influence on the Nu number values. There is almost no difference between predictions from Equation $(4 \mathrm{a}, \mathrm{c})$. The correlation Equation $(4 \mathrm{~b})$ gives slightly different $\mathrm{Nu}$ numbers. The maximum discrepancy is below $3 \%$.

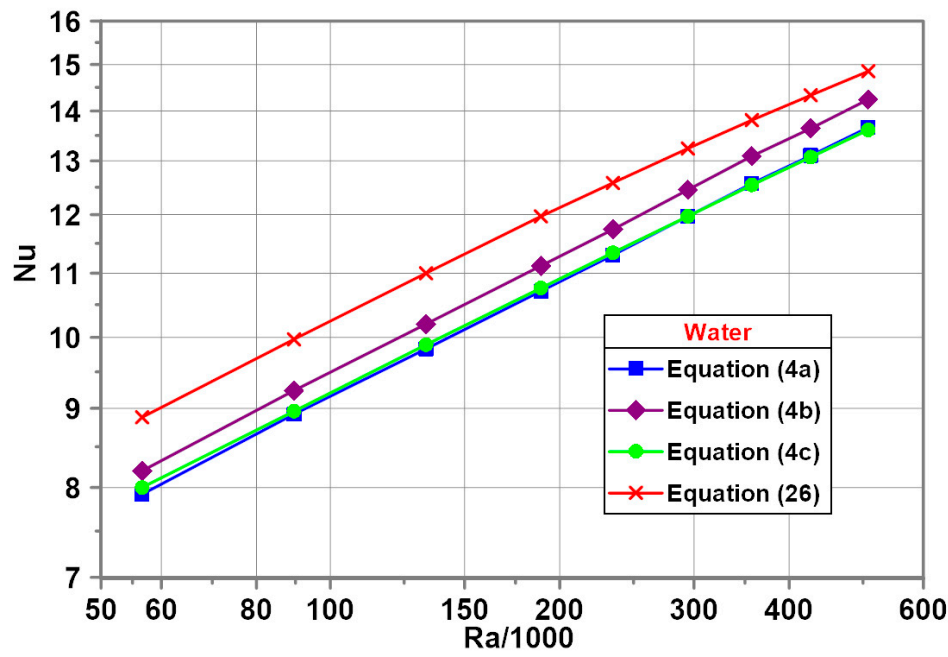

(a)

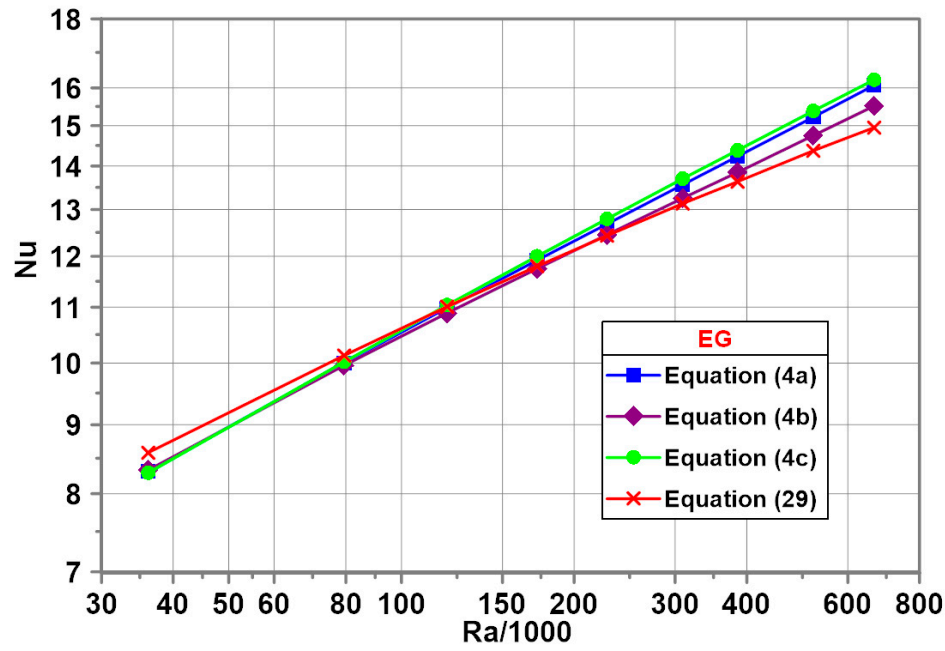

(b)

Figure 11. Impact of characteristic temperature determination on $\mathrm{Nu}$-Ra relationship for water (a) and EG (b). 


\section{Discussion and Conclusions}

The results of experimental investigations of free convection heat transfer for water, EG, and a mixture of water and EG (50:50) by volume from a horizontal cylinder in a rectangular container are presented.

A set of empirical correlation equations for the prediction of $\mathrm{Nu}$ numbers for Rayleigh number range $3.6 \times 10^{4}<\mathrm{Ra}<9.2 \times 10^{5}$ or $3.6 \times 10^{5}<\mathrm{Ra}_{\mathrm{q}}<14.8 \times 10^{6}$ and Pr number range $4.5 \leq \operatorname{Pr} \leq 160$ has been developed.

Predictions from developed correlation equations are compared with predictions from recognized correlation equations for isolated cylinders as well as with recently developed correlation equations which relate Nusselt numbers to Rayleigh numbers and confinement ratios jointly.

The empirical literature correlations based on boundary layer length $b$ gives good estimations of $\mathrm{Nu}$ numbers with a maximum deviation of about $10 \%$.

The influence of submersion depth on free convective heat transfer from isolated cylinders to liquids of high Prandtl numbers is still a research task as, literature correlations are largely for air.

Literature correlations that include wall spacing $\left(\mathrm{S}_{\mathrm{W}} / \mathrm{D}\right)$ show reasonable agreement with present predictions. It seems that the adequacy of the geometry of the thermal system, defined by the confinement ratios, is more significant than the difference in Prandtl number in the prediction of the Nu numbers by different correlations.

New correlation equation, that includes dimensionless distance between periphery of the horizontal cylinder and the bottom wall is needed for liquids of high Prandtl number. For the tested liquids within the range of film temperature $20{ }^{\circ} \mathrm{C} \leq \mathrm{t}_{\mathrm{fm}} \leq 60{ }^{\circ} \mathrm{C}$ the characteristic temperature for which the thermophysical properties of the fluid have been determined has negligible influence on the Nu number estimation.

Author Contributions: Conceptualization, J.T.C.; methodology, J.T.C. and S.S.; software, D.S.; validation, J.T.C. and S.S.; formal analysis, J.T.C.; investigation, D.S.; data curation, D.S.; writing-original draft preparation, J.T.C.; writing-review and editing, J.T.C. and S.S.; funding acquisition, S.S. All authors have read and agreed to the published version of the manuscript.

Funding: This research received no external funding.

Institutional Review Board Statement: Not applicable.

Informed Consent Statement: Not applicable.

Data Availability Statement: Not applicable.

Acknowledgments: The authors thank Albrecht Eicke (City University of Applied Sciences Bremen) for kind cooperation during figures preparation.

Conflicts of Interest: The authors declare no conflict of interest.

\section{Nomenclature}

$\begin{array}{lll}a & \text { Thermal diffusivity } & \left(\mathrm{m}^{2} / \mathrm{s}\right) \\ b=\pi D / 2 & \text { Boundary layer length } & (\mathrm{m}) \\ c_{p} & \text { Specific heat } & (\mathrm{J} /(\mathrm{kg} \mathrm{K})) \\ D & \text { Diameter of heated cylinder } & (\mathrm{m}) \\ G e=g \beta D / c_{p} & \text { Gebhart number } & (-) \\ h & \text { Average heat transfer coefficient } & \left(\mathrm{W} /\left(\mathrm{m}^{2} \mathrm{~K}\right)\right) \\ H & \text { Liquid depth between bottom wall and free liquid surface } & (\mathrm{m}) \\ H_{B} & \text { Distance between periphery of cylinder and bottom wall } & (\mathrm{m}) \\ H_{T} & \text { Submersion depth } & (\mathrm{m}) \\ I & \text { Current } & (\mathrm{A}) \\ k & \text { Thermal conductivity } & (\mathrm{W} /(\mathrm{m} \mathrm{K})) \\ L & \text { Effective length of cylinder } & (\mathrm{m})\end{array}$




$\begin{array}{lll}L_{c h a r} & \text { Characteristic length } & (\mathrm{m}) \\ N u=\frac{h D}{k} & \text { Nusselt number } & (-) \\ P & \text { Electrical power } & (\mathrm{W}) \\ \operatorname{Pr}=\frac{v}{a} & \text { Prandtl number } & (-) \\ q & \text { Heat flux } & \left(\mathrm{W} / \mathrm{m}^{2}\right) \\ R a=\frac{g \beta\left(T_{w}-T_{f}\right) D^{3}}{v a a} & \text { Rayleigh number related to temperature difference } & (-) \\ R a_{b}=\frac{g \beta\left(T_{w}-T_{f}\right) b^{3}}{v a} & \text { Rayleigh number based on } b \text { as characteristic length } & (-) \\ R a_{q}=\frac{g \beta q D^{4}}{k v a} & \text { Rayleigh number related to heat flux } & (-) \\ S_{W} & \text { Distance between periphery of cylinder and side wall } & (\mathrm{m}) \\ t & \text { Temperature } & \left({ }^{\circ} \mathrm{C}\right) \\ T & \text { Temperature } & (\mathrm{K}) \\ \Delta T & \text { Temperature difference } & (\mathrm{K}) \\ U & \text { Voltage } & (\mathrm{V}) \\ W & \text { Width } & (\mathrm{m}) \\ \beta & \text { Thermal expansion coefficient } & (1 / \mathrm{K}) \\ \mu & \text { Dynamic viscosity } & (\mathrm{Pa} \mathrm{s}) \\ v & \text { Kinematic viscosity } & \left(\mathrm{m}^{2} / \mathrm{s}\right) \\ \rho & \text { Density } & \left(\mathrm{kg} / \mathrm{m}^{3}\right) \\ \text { Subscripts } & & \\ c y l & \text { Cylinder } & \\ e l & \text { Electrical } & \\ f & \text { Liquid } & \\ f m & \text { Film temperature } & \\ i n & \text { Inside } & \\ o & \text { Outside } & \\ u n i & \text { Uniform } & \\ v & \text { Volume } & \\ w & \text { Wall } & \\ q & \text { Based on heat flux } & \\ \infty & \text { Infinity } & \end{array}$

\section{References}

1. Boetcher, S.K.S. Natural Convection from Circular Cylinders; Springer Briefs in Thermal Engineering and Applied Science; Springer: Cham, Switzerland, 2014. [CrossRef]

2. Morgan, V.T. The Overall Convective Heat Transfer from Smooth Circular Cylinders. Adv. Heat Transf. 1975, 11, 199-263.

3. Churchill, S.; Usagi, R. A general expression for the correlation of rates of transfer and other phenomena. AICHE J. 1972, 18, 1121-1128. [CrossRef]

4. Churchill, S.; Chu, H. Correlating equations for laminar and turbulent free convection from a horizontal cylinder. Int. J. Heat Mass Transf. 1975, 18, 1049-1053. [CrossRef]

5. Morgan, V.T. Heat transfer by Natural Convection from a Horizontal Isothermal Circular Cylinder in Air. Heat Transf. Eng. 1997, 18, 25-33. [CrossRef]

6. Kuehn, T.H.; Goldstein, R.J. Correlating equations for natural convection heat transfer between horizontal circular cylinders. Int. J. Heat Mass Transf. 1976, 19, 1127-1134. [CrossRef]

7. Fand, R.M.; Morris, E.W.; Lum, M. Natural convection heat transfer from horizontal cylinders to air, water and silicone oils for Rayleigh numbers between $3 \times 10^{2}$ to $2 \times 10^{7}$. Int. J. Heat Mass Transf. 1977, 20, 1173-1184. [CrossRef]

8. Kuehn, T.H.; Goldstein, R.J. Numerical solution to the Navier-Stokes equations for laminar natural convection about a horizontal isothermal circular cylinder. Int. J. Heat Mass Transf. 1980, 23, 971-979. [CrossRef]

9. Farouk, B.; Güçeri, S.I. Natural convection from a horizontal cylinder-laminar regime. Trans. ASME J. Heat Transf. 1981, 103, 522-527. [CrossRef]

10. Fand, R.M.; Brucker, J. A correlation for heat transfer by natural convection from horizontal cylinders that accounts for viscous dissipation. Int. J. Heat Mass Transfer 1983, 26, 709-726. [CrossRef]

11. Sparrow, E.M.; Pfeil, D.R. Enhancement of natural convection heat transfer from a horizontal cylinder due to vertical shrouding surfaces. Trans. ASME J. Heat Transf. 1984, 106, 124-130. [CrossRef]

12. Sparrow, E.M.; Ansari, M.A. All-modes heat transfer from a horizontal cylinder situated adjacent to adiabatic enclosing walls. Int. J. Heat Mass Transf. 1984, 22, 1855-1864. [CrossRef] 
13. Warrington, R.O.; Powe, R.E. The transfer of heat by natural convection between bodies and their enclosures. Int. J. Heat Mass Transf. 1985, 28, 319-330. [CrossRef]

14. Karim, F.; Farouk, B.; Namer, I. Natural Convection Heat Transfer from a Horizontal Cylinder between Vertical Confining Adiabatic Walls. Trans. ASME J. Heat Transf. 1986, 108, 291-298. [CrossRef]

15. Warrington, P.; Smith, S.; Powe, R.; Mussulman, R. Boundary effects on natural convection heat transfer for cylinders and cubes. Int. J. Heat Mass Transf. 1988, 31, 1322-1325. [CrossRef]

16. Ghaddar, N.K. Natural Convection heat transfer between a uniformly heated cylindrical element and its rectangular enclosure. Int. J. Heat Mass Transf. 1992, 35, 2327-2334. [CrossRef]

17. Saitoh, T.; Sajiki, T.; Maruhara, K. Bench mark solutions to natural convection heat transfer problem around a horizontal circular cylinder. Int. J. Heat Mass Transf. 1993, 36, 1251-1259. [CrossRef]

18. Moukalled, F.; Acharya, S. Natural convection in the annulus between concentric horizontal circular and square cylinders. J. Thermophys. Heat Transf. 1996, 10, 524-531. [CrossRef]

19. Kitamura, K.; Kami-iwa, F.; Misumi, T. Heat transfer and fluid flow of natural convection around large horizontal cylinders. Int. J. Heat Mass Transf. 1999, 42, 4093-4106. [CrossRef]

20. Cesini, G.; Paroncini, M.; Cortella, G.; Manzan, M. Natural convection from a horizontal cylinder in a rectangular cavity. Int. J. Heat Mass Transf. 1999, 42, 1801-1811. [CrossRef]

21. Sadeghipour, M.S.; Razi, Y.P. Natural convection from a confined horizontal cylinder: The optimum distance between the confining walls. Int. J. Heat Mass Transf. 2001, 44, 367-374. [CrossRef]

22. Atmane, M.A.; Chan, V.S.S.; Murray, D.B. Natural convection around a horizontal heated cylinder: The effects of vertical confinement. Int. J. Heat Mass Transf. 2003, 46, 3661-3672. [CrossRef]

23. Ashjaee, M.; Eshtiaghi, A.H.; Yaghoubi, M.; Yousefi, T. Experimental investigation on free convection from a horizontal cylinder beneath an adiabatic ceiling. Exp. Therm. Fluid Sci. 2007, 32, 614-623. [CrossRef]

24. Atayılmaz, Ş.Ö.; Teke, İ. Experimental and numerical study of the natural convection from a heated horizontal cylinder. Int. Commun. Heat Mass Transf. 2009, 36, 731-738. [CrossRef]

25. Angeli, D.; Levoni, P.; Barozzi, G.S. Numerical predictions for stable buoyant regimes within a square cavity containing a heated horizontal cylinder. Int. J. Heat Mass Transf. 2008, 51, 553-565. [CrossRef]

26. Kim, B.S.; Lee, D.S.; Ha, M.Y.; Yoon, H.S. A numerical study of natural convection in a square enclosure with a circular cylinder at different vertical locations. Int. J. Heat Mass Transf. 2008, 51, 1888-1906. [CrossRef]

27. Yoon, H.S.; Ha, M.Y.; Kim, B.S.; Yu, D.H. Effect of the position of a circular cylinder in a square enclosure on natural convection at Rayleigh number of $10^{7}$. Phys. Fluids 2009, 21, 047101. [CrossRef]

28. Angeli, D.; Pagano, A.; Corticelli, M.A.; Fichera, A.; Barozzi, G.S. Bifurcations of natural convection flows from an enclosed cylindrical heat source. Front. Heat Mass Transf. 2011, 2, 023003. [CrossRef]

29. Ashjaee, M.; Yazdani, S.; Bigham, S.; Yousefi, T. Experimental and Numerical Investigation on Free Convection from a Horizontal Cylinder Located Above an Adiabatic Surface. Heat Transf. Eng. 2012, 33, 213-224. [CrossRef]

30. Kang, D.H.; Ha, M.Y.; Yoon, H.S.; Choi, C.H. Bifurcation to unsteady natural convection in square enclosure with a circular cylinder at Rayleigh number of $10^{7}$. Int. J. Heat Mass Transf. 2013, 64, 926-944. [CrossRef]

31. Sebastian, G.; Shine, S.R. Natural convection from horizontal heated cylinder with and without horizontal confinement. Int. J. Heat Mass Transf. 2015, 82, 325-334. [CrossRef]

32. Abou-Ziyan, H.; Kalender, A.; Shedid, M.; Abdel-Hameed, H. Experimental investigation of free convection from short horizontal cylinder to Newtonian and power-law liquids of large Prandtl numbers. Exp. Therm. Fluid Sci. 2017, 86, 102-116. [CrossRef]

33. Rath, S.; Dash, M.K.; Dash, S.K. Natural convection from horizontal cylinders of different shapes in a rectangular enclosure. In Proceedings of the 24th National and 2nd International ISHMT-ASTFE Heat and Mass Transfer Conference (IHMTC-2017), Hyderabad, India, 27-30 December 2017.

34. Lin, K.C.; Bhosale, Y.; Huang, C.-Y.Z. 3D-CFD investigation into free convection flow above a heated horizontal cylinder: Comparisons with experimental data. Appl. Therm. Eng. 2017, 120, 277-288. [CrossRef]

35. Ma, H.; He, L.; Rane, S. Heat Transfer-Fluid Flow Interaction in Natural Convection around Heated Cylinder and Its Thermal Chimney Effect. In Proceedings of the International Conference Innovative Applied Energy (IAPE'19), Oxford, UK, 14-15 March 2019.

36. Kuehner, J.P.; Pflug, J.R.; Tessier, F.A., Jr.; Hamed, A.M.; Marin, F.J.M. Velocity measurements in the free convection flow above a heated horizontal cylinder. Int. J. Heat Mass Transf. 2012, 55, 4711-4723. [CrossRef]

37. Fiscaletti, D.; Angeli, D.; Tarozzi, L.; Barozzi, G.S. Buoyancy-induced transitional flows around an enclosed horizontal cylinder: An experiment. Int. J. Heat Mass Transf. 2013, 58, 619-631. [CrossRef]

38. Grafsrønningen, S.; Jensen, A. Natural convection heat transfer from two horizontal cylinders at high Rayleigh numbers. Int. J. Heat Mass Transf. 2012, 55, 5552-5564. [CrossRef]

39. American Society of Heating, Refrigerating and Air-Conditioning Engineers. ASHRAE Handbook-Fundamentals; ASHRAE: Atlanta, GA, USA, 2005.

40. Cieśliński, J.T.; Pudlik, W. Laminar free-convection from spherical segments. Int. J. Heat Fluid Flow 1988, 9, 405-409. [CrossRef]

41. Lewandowski, W.M.; Bieszk, H.; Cieśliński, J.T. Free convection from horizontal screened plates. Wärme-und Stoffübertragung 1992, 27, 481-488. [CrossRef] 
42. Cieśliński, J.T.; Krygier, K. Free convection of water- $\mathrm{Al}_{2} \mathrm{O}_{3}$ nanofluid from horizontal porous coated tube. Key Eng. Mater. 2014, 597, 15-20. [CrossRef]

43. Lienhard, J.H. On the commonality of equations for natural convection from immersed bodies. Int. J. Heat Mass Transf. 1973, 16, 2121-2123. [CrossRef] 